\title{
Pyroxene Spectroscopy Revisited: Spcctral-Compositional Correlations and Relationship to Geothermometry
}

\author{
EDWARD A. CloutTS \\ Department of Geology, University of Alberta, Edmonton, Alberta, Canada \\ MiCHAEI J. GAFFEY \\ Department of Geology, Rensselaer Polytechnic Institute, Troy, New York
}

\begin{abstract}
Pyroxene reflectance and transmittance spectra have been examined in a search for systematic relationships between spectral features and compositional variations and to assess the applicability of reflectance spectroscopy to pyroxene geothermometry. Orthopyroxenes containing up to $\sim 11 \%$ Wollastonite show a positive correlation between $\mathrm{Fe}^{2+}$ content and wavelength positions of the major absorption bands. Aluminum-rich orthopyroxenes display absorption bands at lower than expected wavelengths. Spectral-compositional relationships are more complex for clinopyroxenes, showing both positive and negative correlations between band positions and major cation abundances. These relationships are further complicated by the presence of significant amounts of other transition series elements such as $\mathrm{Ti}$ and $\mathrm{Cr}$ and by the presence of exsolved phases and compositional zonations. Even small-scale exsolutions $(<1 \mu \mathrm{m}$ wide) seem to be sufficient to significantly alter spectral properties. Contours of the wavelength positions of band minima projected onto the pyroxene tetralateral generally exhibit concave downward shapes. The orientations of the contours relative to pyroxene geotherms are such as to effectively preclude the use of spectroscopy to significantly constrain the temperatures of formation of pyroxenes.
\end{abstract}

\section{INTRODUCTION}

Pyroxenes are among the most ubiquitous minerals present on the surfaces of inner solar system bodies. They are known or inferred to exist on the surfaces of Mercury [McCord and Clark, 1979], Venus [Surkov et al., 1983], the Earth and moon [Basaltic Volcantsm Study Project, 1981], Mars [Wood and Ashwal, 1981; Huguenin, 1987; Singer et al., 1990], and certain classes of asteroids [McCord et al., 1970; Feterberg et al., 1980; Crutkshank et al., 1991] and meteorites [e.g., Dodd, 1981].

Spectroscopic remote sensing is one of the most powerful techniques for determining the surface compositions of inaccessible targets. Given the widespread presence of pyroxenes, it is important that their spectral reflectance properties be well understood in order to maximize the compositional information which can be obtained through spectroscopic remote sensing. Compositional information is important for constraining the history of a target; in the case of pyroxenes, compositional information is of most relevance for deducing the thermal history of an object. Compositional information can be obtained by spectroscopic means at a number of wavelength intervals, but one of the most useful is from -0.3 to $-2.6 \mu \mathrm{m}$ because solar flux is high and the atmosphere is largely transparent over this range.

The spectral reflectance and transmittance properties of pyroxenes, both orthopyroxenes (OPX) and clinopyroxenes (CPX), have been the subject of a large number of studies and the relationships between spectral and material properties are generally well understood. There are, however, areas of

${ }^{2}$ Permanently at Calgary, Alberta, Canada.

Copyright 1991 by the American Geophysical Union.

Paper number 91JE02512.

0148-0227/91/91JE-02512\$05.00 disagreement, and some of the quantitative relationships are poorly constrained. Much less information is available concerning the spectral reflectance properties of OPX-CPX mixtures. This paper reexamines the various correlations purported to exist between pyroxene compositional variations and changes in spectral reflectance properties through a review of existing spectral data augmented by new results. The observed trends and relationships are compared to pyroxene geotherms in order to assess whether reflectance spectroscopy can be used to derive geothermometric information.

A detailed discussion of pyroxene nomenclature is beyond the scope of this paper. Excellent reviews on the subject can be found in the works by Cameron and Paplke [1980] and Morlmoto et al. [1988]. The most basic division of pyroxenes is between orthopyroxenes and clinopyroxenes and is based on compositional and structural differences. By this scheme. orthopyroxenes are essentially those samples containing $<5 \mathrm{~mol}$ $\% \mathrm{CaSiO}$, (wollastonite, Wo) and possessing orthorhombic symmetry, while clinopyroxenes can contain between 0 and 50 $\mathrm{mol} \%$ Wo and possess monoclinic symmetry [Morlmoto et al., 1988].

\section{PREVIOUS STUDIES OF PYROXENE SPECTRA}

Orthopyroxene and clinopyroxene exhibit differences in spectral properties which are related to differences in composition and structure. Both groups have been intensively studied, and the basic relationships between abundances of major cations and spectral changes are fairly well understood for many regions of the pyroxene tetralateral.

\section{Orthopyroxenes}

Orthopyroxene reflectance spectra in the 0.3- to $2.6-\mu \mathrm{m}$ region are characterized by two major absorption bands situated near $0.9 \mu \mathrm{m}$ (band I) and $1.9 \mu \mathrm{m}$ (band II) which are of roughly equal intensity (Figure 1) and are attributable to crystal field transitions in ferrous iron which preferentially 


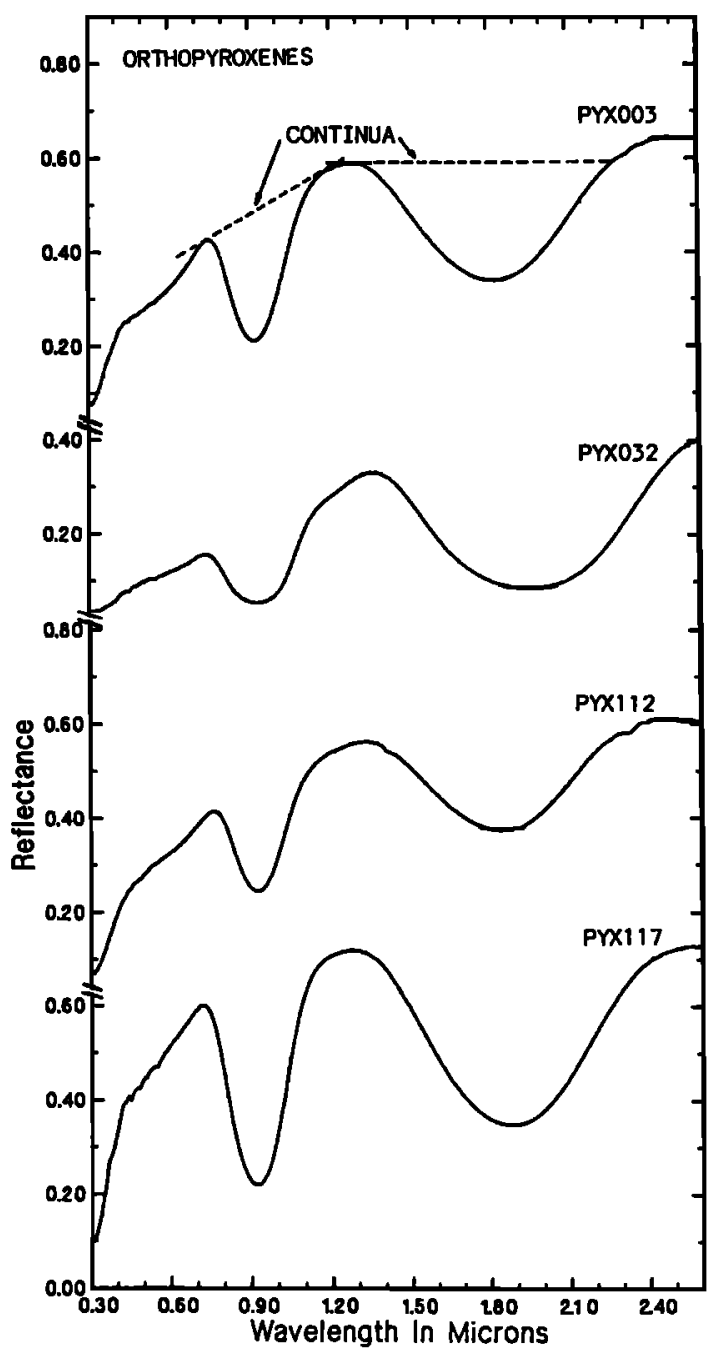

Fig. 1. Reflectance spectra of some low-calcium content pyroxenes (orthopyroxenes) measured at RELAB. PYX032 is a $45-90 \mu \mathrm{m}$ sized sample. All others are $<45-\mu \mathrm{m}-$ sized samples. Compositions are given in Table 1.

occupies the M2 crystallographic site [e.8., Clark, 1957; Ghose, 1965; White and Keester, 1966; Bancroft and Burns, 1967; Bancroft et al., 1967; Burns, 1970; Burns et al., 1972a, b; Roush, 1984]. Both major absorption bands shift to longer wavelengths with increasing ferrous iron content [Adams and McCord, 1972; Adoms, 1974; Cloutts, 1985; Aoyama et al., 1987]. For both orthopyroxenes and clinopyroxenes, increasing particle size results in a decrease in overall reflectance and an increase in absorption band depth until the bands become saturated [Adams and Fllice, 1967; Hunt and Sallsbury, 1970; Pleters, 1974].

The steep reflectance dropoff shortward of $-0.5 \mu \mathrm{m}$ is attributable to charge transfers involving a variety of atomic species. A number of weak absorption bands are of ten evident at shorter wavelengths $(<0.7 \mu \mathrm{m})$ and are ascribed to various electronic processes involving a number of cations, with frequent disagreements over precise assignments [Burns, 1970; Burns et al., 1972a, b; Runctman et al., 1973; Rossman, 1977; Hozen et al., 1978].

\section{Clinopyroxenes}

Clinopyroxene spectra can broadly be assigned to one of two types (type $A$ and type B) on the basis of their absorption bands. Type B spectra (Figure 2) are superficially similar to orthopyroxenes (Figure 1), the former exhibiting two major absorption bands near $1.05 \mu \mathrm{m}$ (band I) and $2.35 \mathrm{\mu m}$ (band II). Calcium is strongly partitioned into the $\mathbf{M} 2$ crystallographic site with iron of ten making up any deficiencies in calcium M2 site occupancy [Warren and Brags, 1929; Bancroft et al., 1967]. As with OPX, both CPX absorption bands are attributed to crystal field transitions in ferrous iron situated in the $\mathrm{M}_{2}$ crystallographic site [Burns, 1970; Hazen et al., 1978; Rossman,

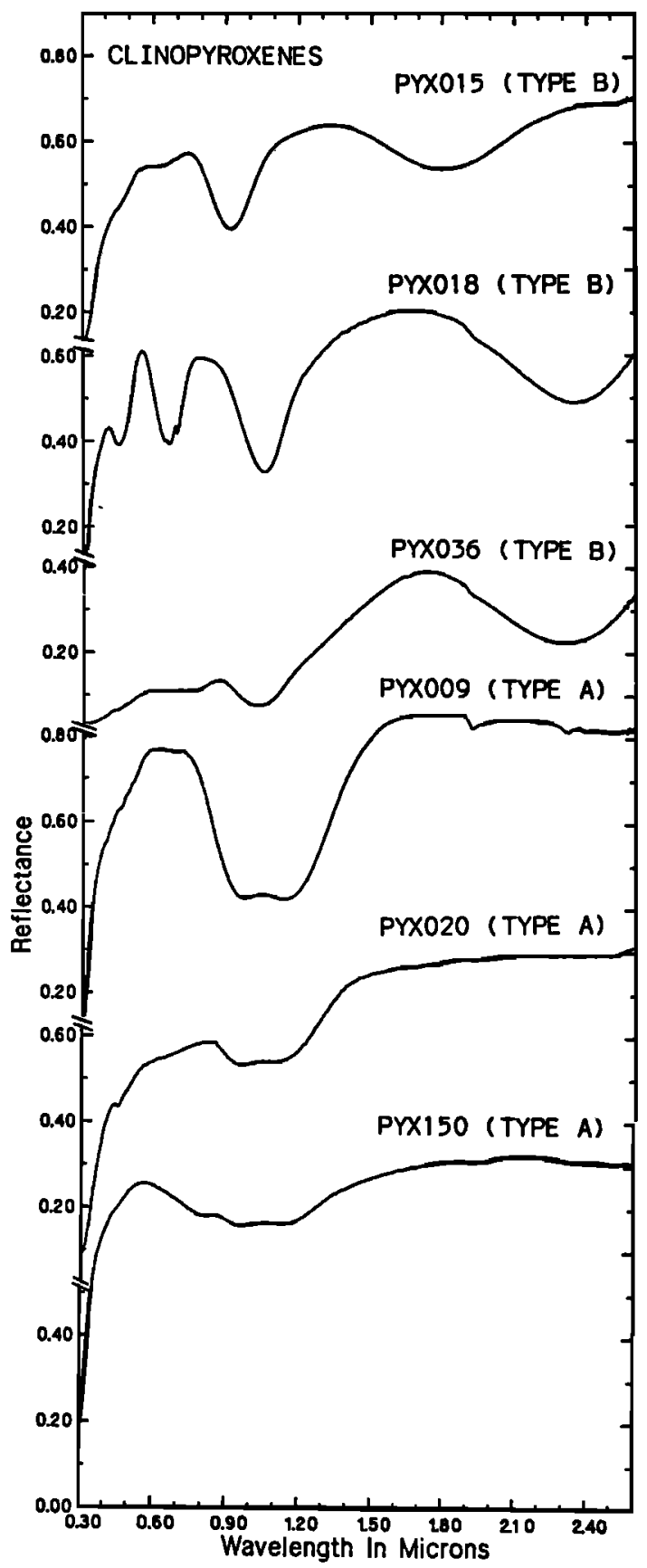

Fig. 2. Reflectance spectra of some high-calcium content pyroxenes (clinopyroxenes) measured at RELAB. Spectral type $\mathrm{B}=$ PYX015, PYX018, PYX036 (upper 3 spectra); spectral type $A=$ PYX009, PYX020, PYX150 (lower 3 spectra). Grain sizes of samples: PYX015 = <45 $\mu \mathrm{m}$, PYX018 $=45-90 \mu \mathrm{m}, \mathrm{PYX036}=45.90 \mu \mathrm{m}, \mathrm{PYX009}=45.90$ $\mu \mathrm{m}, \mathrm{PYX} 020=45-90 \mu \mathrm{m}, \mathrm{PYX} 150=<45 \mu \mathrm{m}$. Compositions are given in Table 1. 


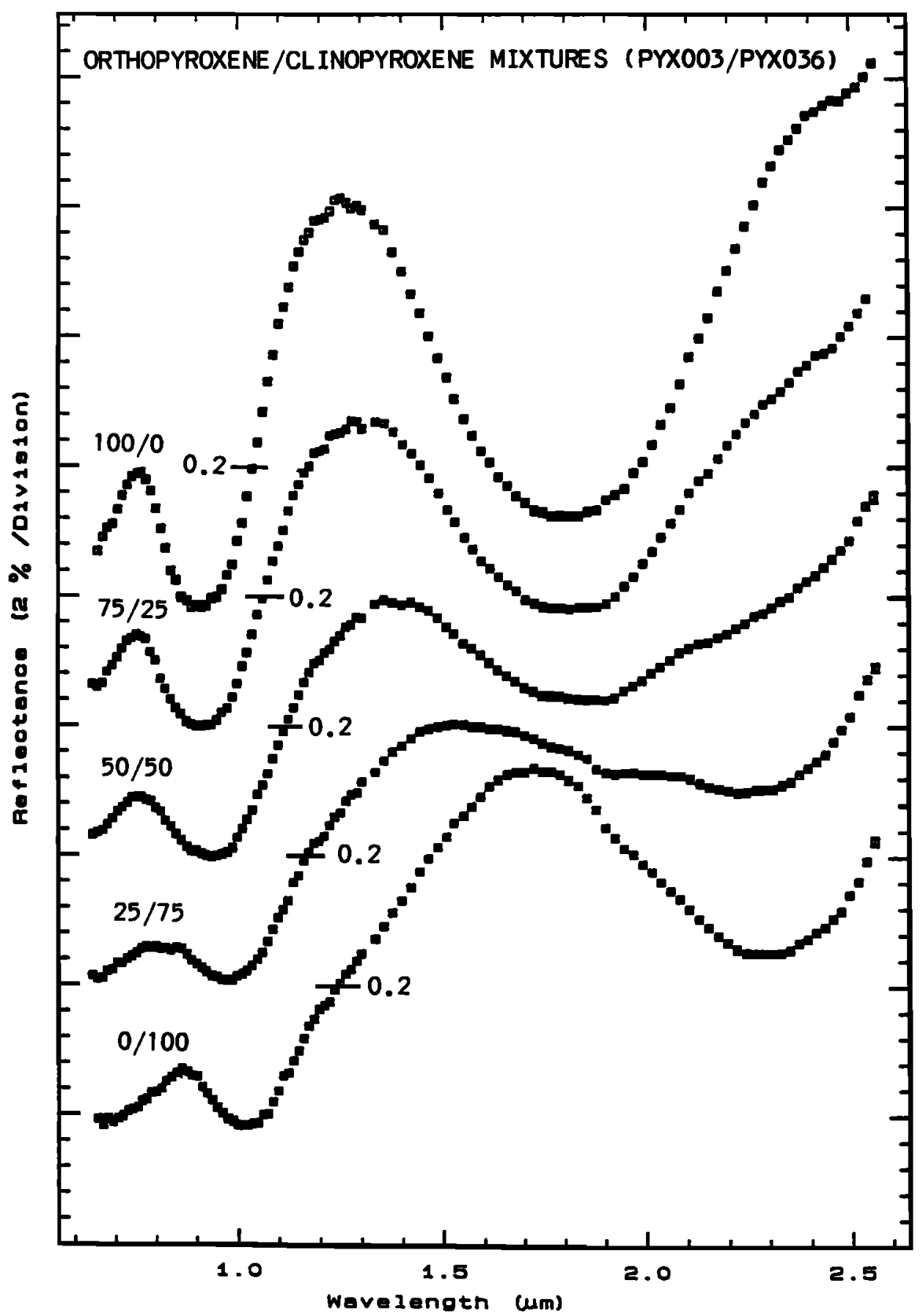

Fig. 3. Reflectance spectra of two series of $25 \mathrm{wt} \%$ interval mixtures of OPX + CPX (45-90 $\mu \mathrm{m}$ grain size) measured at the University of Hawaii. PYX003, PYX032 = orthopyroxenes, PYX036, PYX040= clinopyroxenes. The point on the spectrum of $20 \%$ reflectance $(0.2)$ is indicated for each curve.

1980]. The wavelength positions of the main $\mathrm{Fe}^{2+}$ absorption bands in type $\mathrm{B}$ spectra are correlated with $\mathrm{Fe}^{2+}$ and $\mathrm{Ca}$ contents and are dealt with in greater detail in a subsequent section.

Type A CPX spectra exhibit two main absorption bands near 0.9 and $1.15 \mu \mathrm{m}$ which partially overlap (Figure 2). These bands are assigned to crystal field transitions in ferrous iron situated in the M1 crystallographic site [Burns, 1970; Adams, 1975]. CPX spectra intermediate between type $A$ and type B are also possible and indicate spectral contributions from ferrous iron situated in both the M1 and M2 sites [White and Keester, 1966; Bell and Mao, 1972; Burns et al., 1972b].
Many CPX spectra exhibit an additional absorption band near $0.8 \mu \mathrm{m}$ due to $\mathrm{Fe}^{2+}-\mathrm{Fe}^{3+}$ charge transfers and weaker absorption bands at shorter wavelengths due to various charge transfers and crystal field transitions [Burns, 1970; Adams and McCord, 1972; Burns et al., 1972b; Adams, 1974, 1975; Hezen et al., 1978; Rossman, 1980). The reflectance decrease shortward of $-0.7 \mu \mathrm{m}$ is again assigned to various charge transfers.

\section{Orthopyroxene-Clinopyroxene Maxtures}

The reflectance spectra of OPX-CPX mixtures have not been intensively studied, but the data available for intimate 


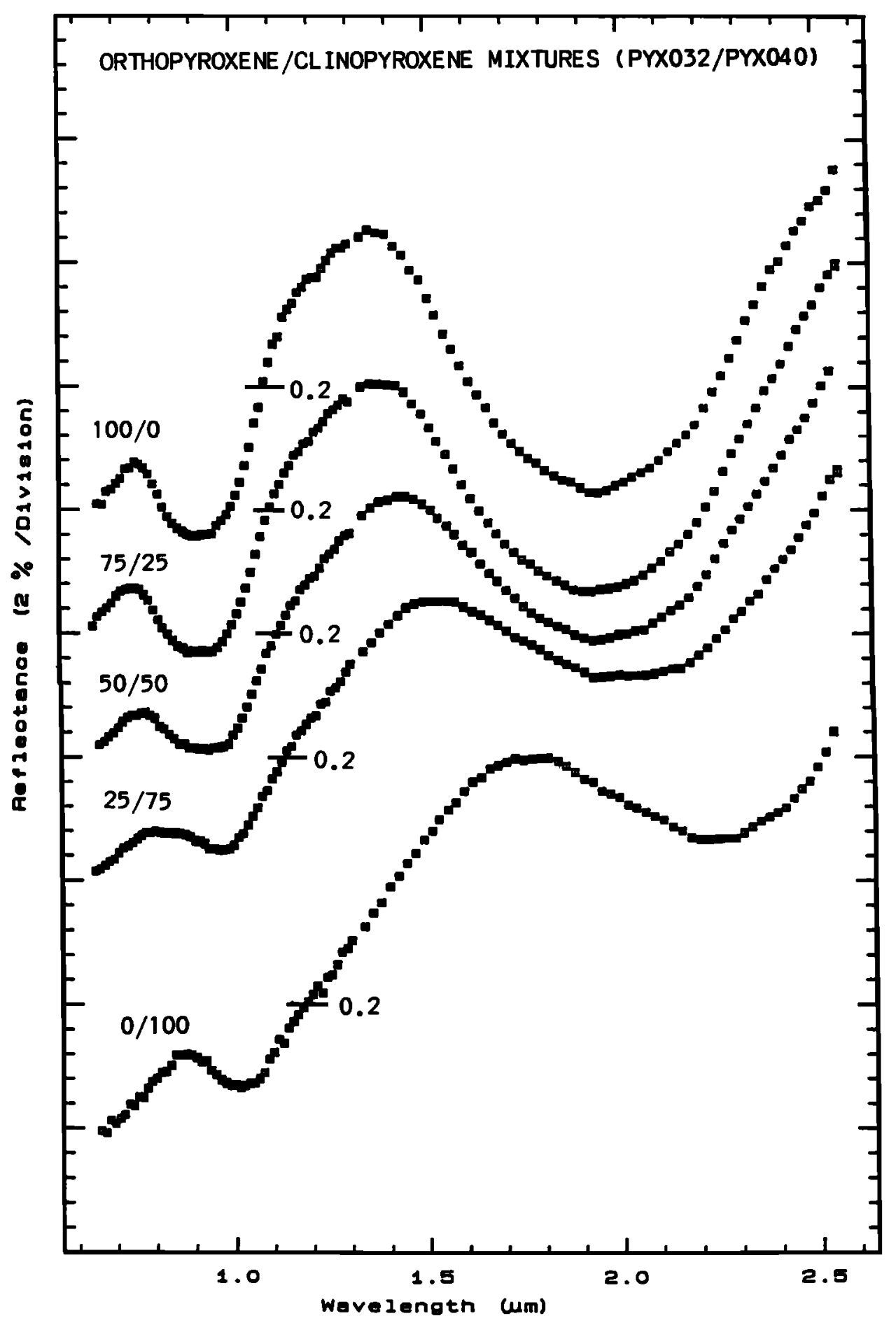

Fig. 3. (continued)

particulate mixtures of OPX and spectral type B CPX indicate that their reflectance spectra are intermediate between the two end-members (Figure 3 ) and are not simple additive combinations of the end-member spectra [Adams, 1975; Stnger, 1981; Johnson et al., 1983; Cloutts, 1985; Sunshine et al., 1990]. The large degree of overlap between OPX and CPX absorption bands results in complex, asymmetric absorption features.

\section{EXPERIMENTAL PROCEDURE}

A number of naturally occurring terrestrial pyroxenes have been spectrally characterized for this study, both as pure phases and in mixtures. The compositions of the pyroxenes have been obtained by electron microprobe analysis at the University of Calgary SEMQ electron microprobe facility and are an average of four-eight point analyses and area scans. Some representative analyses are presented in Table 1 . The data were reduced using Bence-Albee $\boldsymbol{\alpha}$ and $\boldsymbol{\beta}$ correction factors. The $\mathrm{Fe}^{2+}$ values were determined by wet chemical methods, and $\mathrm{Fe}^{3+}$ as the difference between total and ferrous iron. The sample powders used for spectral analysis were prepared by crushing the minerals in an alumina mortar and pestle. Nonpyroxene phases present in the samples consisted largely of opaque minerals such as magnetite and various alteration products and were removed through a combination 
TABLE 1a. Chemical Analyses of Some of the Pyroxenes Used in this Study

\begin{tabular}{|c|c|c|c|c|c|c|}
\hline & PYX003 & PYX009 & PYX015 & PYX018 & PYX020 & PYX032 \\
\hline $\mathrm{SiO}_{2}$ & 50.33 & 53.90 & 52.07 & 55.17 & 55.23 & 50.21 \\
\hline $\mathrm{Al}_{2} \mathrm{O}$ & 5.46 & 0.51 & 6.34 & 0.37 & 0.59 & 1.24 \\
\hline $\mathrm{FeO}$ & 17.30 & 6.20 & 3.25 & 2.42 & 2.07 & 23.65 \\
\hline $\mathrm{Fe}_{2} \mathrm{O}_{3}$ & 1.43 & 0.00 & 0.01 & 0.00 & 0.00 & 5.11 \\
\hline $\mathrm{MgO}$ & 23.58 & 14.18 & 16.42 & 17.01 & 17.06 & 17.57 \\
\hline $\mathrm{CaO}$ & 1.59 & 25.08 & 19.38 & 23.93 & 24.08 & 1.59 \\
\hline $\mathrm{Na}_{2} \mathrm{O}$ & 0.05 & 0.05 & 1.31 & 0.51 & 0.52 & 0.00 \\
\hline $\mathrm{TiO}_{2}$ & 0.41 & 0.01 & 0.21 & tr. & 0.09 & 0.19 \\
\hline $\mathrm{CI}_{2} \mathrm{O}_{3}$ & 0.11 & 0.04 & 1.39 & 0.91 & 0.96 & 0.04 \\
\hline $\mathrm{V}_{2} \mathrm{O}_{3}$ & 0.02 & 0.02 & 0.03 & 0.03 & 0.05 & tr. \\
\hline $\mathrm{COO}$ & 0.04 & 0.05 & 0.03 & 0.02 & 0.05 & 0.06 \\
\hline NiO & 0.01 & 0.15 & 0.07 & 0.07 & 0.06 & 0.01 \\
\hline $\mathrm{MnO}$ & 0.29 & 0.26 & 0.10 & 0.10 & 0.10 & 0.53 \\
\hline Total & 100.62 & 100.45 & 100.61 & 100.54 & 100.86 & 100.20 \\
\hline En & 68.5 & 39.8 & 51.0 & 47.8 & 48.0 & 54.9 \\
\hline Fs & 28.2 & 9.7 & 5.6 & 3.8 & 3.3 & 41.5 \\
\hline Wo & 3.3 & 50.5 & 43.4 & 48.4 & 48.7 & 3.6 \\
\hline
\end{tabular}

Here tr. $=<0.01 \mathrm{wt} \%$.

of hand picking and magnetic separation. The cleaned separates were repeatedly wet sieved with acetone to obtain well sorted size fractions. The various mineral mixtures were prepared on a weight percentage basis (e.8., a mixture of 75 wt \% OPX and 25 wt \% CPX would be expressed as $75 / 25$ OPX/CPX).

The reflectance spectra were measured at the Reflectance Experiment Laboratory (RELAB) spectrometer facility at

TABLE 1b. Chemical Analyses of Some of the Pyroxenes Used in this Study

PYX036 PYX040 PYX103 PYX112 PYX115 PYX117

\begin{tabular}{lrrrrrr}
\hline $\mathrm{SiO}_{2}$ & 50.54 & 47.27 & 52.06 & 49.99 & 51.82 & 53.54 \\
$\mathrm{Al}_{2} \mathrm{O}_{3}$ & 2.99 & 8.28 & 0.98 & 6.21 & 1.96 & 1.54 \\
$\mathrm{FeO}$ & 8.18 & 4.69 & 11.38 & 16.56 & 10.46 & 16.17 \\
$\mathrm{Fe}_{2} \mathrm{O}_{3}$ & 1.71 & 2.77 & 1.32 & 0.58 & 0.22 & 1.02 \\
$\mathrm{MgO}$ & 14.64 & 13.19 & 13.96 & 22.31 & 16.04 & 27.53 \\
$\mathrm{CaO}$ & 20.35 & 20.90 & 19.31 & 3.99 & 18.00 & 0.35 \\
$\mathrm{Na}_{2} \mathrm{O}$ & 0.27 & 0.63 & 0.22 & 0.06 & 0.19 & 0.00 \\
$\mathrm{TiO}_{2}$ & 0.86 & 1.73 & 0.35 & 0.53 & 0.84 & 0.03 \\
$\mathrm{Cr}_{2} \mathrm{O}_{3}$ & 0.07 & 0.43 & 0.07 & 0.13 & 0.09 & 0.07 \\
$\mathrm{~V}_{2} \mathrm{O}_{3}$ & 0.08 & tr. & 0.06 & 0.00 & 0.05 & 0.00 \\
$\mathrm{CoO}$ & 0.04 & 0.03 & 0.05 & 0.04 & 0.06 & 0.01 \\
$\mathrm{NiO}$ & 0.02 & 0.03 & 0.04 & 0.03 & 0.05 & 0.05 \\
$\mathrm{MnO}$ & 0.25 & 0.11 & 0.29 & 0.26 & 0.24 & 0.44 \\
& & & & & & \\
$\mathrm{Total}$ & 100.00 & 100.06 & 100.09 & 100.69 & 100.02 & 100.75 \\
& & & & & & \\
$\mathrm{En}$ & 43.3 & 42.7 & 40.8 & 64.8 & 46.0 & 74.7 \\
$\mathrm{Fs}$ & 13.4 & 8.5 & 18.7 & 26.9 & 16.9 & 24.6 \\
$\mathrm{Wo}$ & 43.3 & 48.8 & 40.5 & 8.3 & 37.1 & 0.7 \\
\hline
\end{tabular}

PYX112 = Smithsonian Institution MNH B18247.

Here tr. $=<0.01 \mathrm{wt} \%$.
Brown University and at the University of Hewaii spectrometer facility. Details of the instruments are given by Pleters [1983] and Singer [1981], respectively. Spectral resolution is $5 \mathrm{~nm}$ and $-1.5 \%$, respectively. The RELAB spectra have been measured at an incidence angle of $30^{\circ}$ and emission angle of $0^{\circ}$, while the University of Hawaii spectra have been measured at $0^{\circ}$ incidence and 15 emission. All spectra have been measured relative to halon, a near-perfect diffuse reflector in the 0.3- to 2.7- $\mathrm{mm}$ wavelength range [Weldner and Hsta, 1981], and corrected for minor $(-2 \%)$ irregularities in halon's absolute reflectance in the $2-\mu \mathrm{m}$ region as well as for dark current offsets. The reflectance spectra have been processed using the Gaffey Spectrum Processing System, a personal computer compatible version of SPECPR [Clark, 1980].

Continuum removal has been performed by dividing out a straight-line continuum tangent to the reflectance spectrum on either side of an absorption feature. For band II, because the long wavelength wing of the band is usually incomplete, a horizontal continuum was constructed tangent to the reflectance spectra at the reflectance maxima between band I and band II. The various continua used to isolate absorption bands are shown superimposed on the PYX003 spectrum in Figure 1 as an example. Band center is defined as the wavelength position of the point of lowest reflectance after division by the continuum, while band minimum is the point of least reflectance with no continuum removel. Band centers and band minima have been calculated by fitting a quadratic function to 10-20 data points on either side of a visually determined approximate center or minimum.

\section{ANALYSIS OF PREVIOUSLY PUBLISHED DATA}

In addition to the reflectance spectra measured for this study the data from a number of previous spectral studies were incorporated [Adams, 1974, 1975; Nash and Conel, 1974; Gaffey, 1976; Hazen et al., 1978]. A number of other pyroxene reflectance spectra are available in the literature but were not included in this study because the spectral data were not of sufficient quality to accurately measure band positions or because sample compositions had not been adequately characterized.

For the studies cited above the band position data from the Adams [1974, 1975] studies were provided by T. L. Roush at the NASA Ames Research Centet. The band positions of the Nash and Conel [1974] pyroxene spectrum were measured directly from the published figure, the bend positions of the pyroxene spectra in the Gaffey [1976] study were measured from the original figures, and the band positions of the Haren et al. [1978] spectra were taken from the tabilated results presented in their paper.

The accuracy of the Adams [1974, 1975] spectra have been the subject of much recent debate. An apparent problem with the wavelength accuracy of the spectra was first noted by McFadden el al. [1982]. They stated that the Adams spectra were apparently shifted to shorter than expected wavelengths on the basis of the compositional information. Since that time there has been a lively discussion of the problem with a number of suggestions made as to the nature, cause, and magnitude of the discrepancy, but the ptoblem has yet to be resolved. Recent indications that the original samples will be remeasured should eventually lead to a resolution of the problem. Until such time as the cause and magnitude of the wavelength disctepancy are determined the following "correction" has been applied to the Adams data in order to be able to derive some measure of useful information. A comparison of the wavelength positions of the band I and band II minima as a 
function of ferrous iron and calcium contents of the original Adams data and more recent spectra measured by a number of investigators using different spectrometers suggested that the wavelength of fet was on the order of $13 \mathrm{~nm}$ across the entire spectral range [Cloutts, 1985]; i.e., the Adams data were shifted to shorter than expected wavelengths by this amount relative to the results obtained by other investigators. Other researchers have suggested that the wavelength shift may be greater than $13 \mathrm{~nm}$, may only affect some of the data, and/or the shift may be restricted to a limited wavelength interval. Therefore, until such time as the original samples are recharacterized, in the absence of a definitive resolution of this issue, and for the purposes of this study, the Adams data have all been shifted to longer wavelengths by $13 \mathrm{~nm}$.

\section{RESULTS}

Since the first comprehensive study of pyroxene reflectance spectra by Adams [1974], the number of available pyroxene reflectance spectra in the literature for which good compositional information exists has approximately doubled. This data set is also augmented by the availability of a large number of pyroxene transmission spectra which are particularly valuable for filling in gaps in the pyroxene tetralateral in the intermediate calcium and high-iron regions for which reflectance spectra are lacking [Hazen et al., 1978].

There is no well-defined hiatus between reflectance spectra exhibiting OPX or CPX spectral characteristics. In the region of intermediate calcium content (11-30\% Wo), in particular, many pyroxenes exhibit reflectance spectra possessing features characteristic of both orthopyroxenes and clinopyroxenes. For the purposes of this paper, conventional interpretations [Adams, 1974] have been followed by referring to low-calcium content pyroxenes $(<-11 \% \mathrm{Wo})$ as orthopyroxenes.

\section{Orthopyroxene Spectra}

The orthopyroxene reflectance spectra measured for this study all exhibit the familiar two-band structure (Figure 1). Absorption band data from this study, Adans [1974, 1975], Nash and Conel [1974], Gaffey [1976], and transmission spectra from Hazen et al. [1978] have been combined to examine correlations between the wavelength positions of absorption band minima and ferrous iron content and to determine the maximum $\mathrm{Ca}$ content which can be accomodated into a pyroxene without disrupting the observed trends between spectral features and compositional variations for orthopyroxenes. The previously discussed "correction" has been applied to the data of Adams [1974, 1975]; i.e., the spectra have been shifted to longer wavelengths by $13 \mathrm{~nm}$.

The somewhat limited data available for pyroxenes containing -5-15\% Wo suggest that pyroxenes containing up to -11 wt \% Wo fall along the trends relating band minima to ferrous iron content for the lower calcium content pyroxenes (orthopyroxenes) (Figure 4). Adams [1974] derived a similar value based on his examination of pyroxene spectra, noting that pyroxenes containing $<-10 \%$ Wo show a well-defined relationship between the wavelength positions of the band minima and ferrous iron content. Burns et al. [1972b] noted a similar relationship as well as noting the spectral heterogeneity of pyroxenes in the central portion of the tetralateral. Both band I and band II minima wavelength positions increase with increasing ferrous iron content and this trend can be used to determine the ferrous tron content of low-calcium content pyroxenes $(<-11 \mathrm{wt} \% \mathrm{Wo})$ from diffuse reflectance spectra. This correlation has been known for some time [Adams and McCord, 1972] and has been improved upon on the basis of more extensive data sets [Adams, 1974, 1975; Gaffey, 1976; Cloutts, 1985; Aoyama et al., 1987].

Comparisons of band minima to continuum removed band centers indicate that band centers occur, on average, $7 \mathrm{~nm}$ higher than band minima. If this difference is not taken into account, the ferrous iron contents of orthopyroxenes could be overestimated by as much as $\mathbf{2 0} \mathrm{mol} \%$ if band centers are used to determine iron content in a correlation which is based on band minima such as shown in Figure 4.

High-aluminum content orthopyroxenes seem to fall below the orthopyroxene trends based on band positions, particularly for band II (Figure 4), a discrepancy first noted by Adans [1974]. While the available aluminum rich orthopytoxene spectral set is limited (six samples), it appears that increasing aluminum content is inversely correlated with band position, opposite the trend seen for ferrous iron. The data suggest that every $1 \mathrm{wt} \%$ increase in $\mathrm{Al}_{2} \mathrm{O}$, is spectrally equivalent to a $5 \mathrm{wt}$ \% decrease in ferrosilite (Fs) content [Cloutts et al., 1990a]. This systematic variation may be of particular significance to lunar remote sensing because lunar pyroxenes commonly contain a few weight percent aluminum [Adams and McCord, 1972; Paplke et al., 1976]. No consistent spectral parameter has yet been found to distinguish low - from high-aluminum orthopyroxene. Thus correlations based on the wavelength positions of absorption bands provide only a lower limit on the ferrous iron contents of orthopyroxenes and pigeonites [Cloutis et al., $1990 a]$.

Absorption band depths are expected to increase with increasing mean grain size. A plot of the reflectance ratio of the interband peak to the band I minimum illustrates that band depth measured in this way increases with increasing grain size for any one sample (Figure 5). Band depth has been measured as the ratio of the reflectance maximum at the peak between band I and band II to the reflectance of the band I minimum. Reflectance ratios are the most sensitive indicators of grain size variations in the absence of absolute reflectance data which are of ten unavailable [Adams and Filice, 1967; Cloutis et al., 1986]. However, pyroxenes with small mean grain sizes ( $<150$ $\mu \mathrm{m}$ ) show a wide range in this reflectance ratio. Samples with large mean grain sizes $(>600 \mu \mathrm{m})$ generally exhibit reflectance ratios $>4$, although the spectral data for large grain size pyroxenes are very limited. This relationship does not provide stringent constraints on grain size but given the quality and quantity of the data suggests that a reflectance ratio $<4$ is indicative of a smaller grain size; however, the opposite case does not hold true. Further work is required to define a more useful criterion for establishing mean grain sizes.

The presence of opaque phases mixed with pyroxene will reduce reflectance ratios [Clouts et al., 1990a, b], and if opaques are suspected or known, only a lower limit on grain sizes can be determined. Very large mean grain sizes may also be inferred by whether the absorption bands appear saturated. This is commonly recognized by noting whether the bottoms of absorption bands appear flattened. Mean grain sizes on the order of $200 \mu \mathrm{m}$ may result in saturated absorption bands [Hunt and Sallsbury, 1970; Pteters, 1983]. However, in most remote sensing situations, such as the examination of planetary regoliths, a range of grain sizes are expected to be present. Reflectance spectra of assemblages containing a range of grain sizes are dominated by the finer fractions, so that band saturation effects are not expected to be common [Cloutls, 1985].

\section{Clinopyroxene Spectra}

Clinopyroxene spectra are much more variable than orthopyroxene spectra and two main spectral types have been 

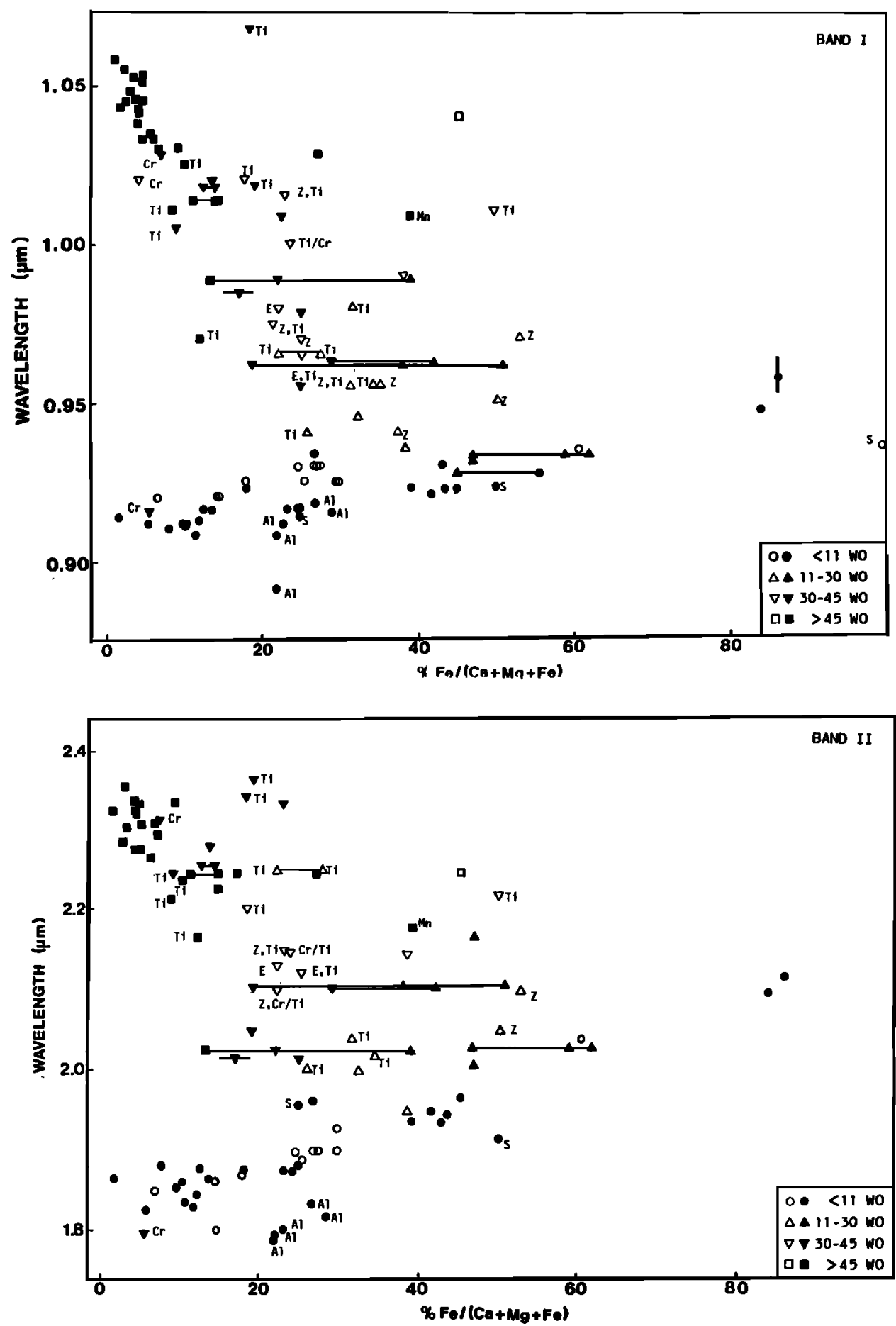

Fig. 4. Wavelength positions of (upper) band I and (lower) band II minima of orthopyroxenes and type B clinopyroxenes as a function of ferrosilite (Fs) content (i.e., $\mathrm{Fs}=\mathrm{Fe}^{2+} /\left(\mathrm{Ca}+\mathrm{Mg}+\mathrm{Fe}^{2+}\right)$. Open symbols indicate transmission spectra, filled symbols indicate reflectance spectra. The data have been subdivided into four groups on the basis of wollastonite (Wo) content. $\mathrm{Ti}=$ semples containing $>1$ wt $\% \mathrm{TiO}, \mathrm{Cr}=$ samples containing $>1$ wt $\% \mathrm{Cr}_{2} \mathrm{O}_{3}, \mathrm{Mn}=$ samples containing $>5 \mathrm{wt} \% \mathrm{Mn}, E=$ samples known to contain exsolved phases, $Z=$ strongly zoned samples, $\mathrm{Al}=$ orthopyroxenes containing $>4 \mathrm{wt} \% \mathrm{Al}_{2} \mathrm{O}_{3}, S=$ synthetic samples. Vertical lines indicate uncertainties in band position, horizontal lines connect end-member compositions of zoned or exsolved samples. Sources of data: Nash and Conel [1974], Adams [1974, 1975], Gaffey [1976], Hazen et al. [1978], Mi yamoto et al. [1983], and this study.

identified (type $A$ and type B)[Adams, 1975]. At the time it was stated that there appeared to be no obvious compositional differences to account for the spectral differences. The differences are primarily a function of the relative occupancies of the M1 and M2 crystallographic sites by transition series elements, particularly $\mathrm{Fe}^{2+}$, which is in turn dependent on factors such as calcium and ferric iron contents [Rossman, 1980]. A compilation of available clinopyroxene spectra for which good compositional data exist indicates that, in general, spectral type A CPX contain $>-50 \% \mathrm{Ca} /\left(\mathrm{Ca}+\mathrm{Mg}+\mathrm{Fe}^{2+}\right)$, while 


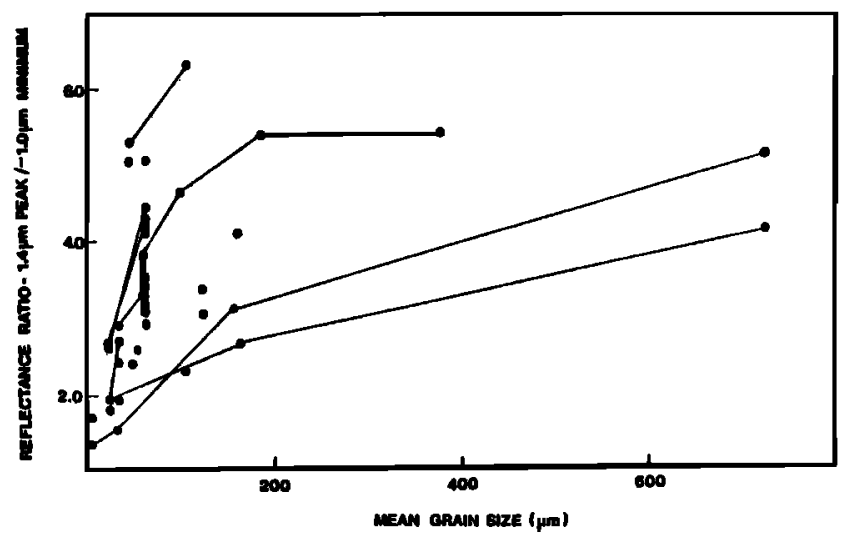

Fig. 5. Ratio of the absolute reflectance of the maximum between band I and band II to the reflectance of the band I minimum as a function of average grain size for orthopyroxenes. Lines connect different grain sizes of a single sample. Sources of data: Hunt and Sallsbury [1970], Adams [1974], Pleters [1983], and this study.

type B CPX contain <-50\% $\mathrm{Ca} /\left(\mathrm{Ca}+\mathrm{Mg}+\mathrm{Fe}^{2+}\right.$ ) (Figure 6) with a degree of overlap between the two groups. The overlap is due to the fact that, as mentioned, calcium content is not the only factor controlling $\mathrm{Fe}^{2+}$ site occupancies.

The reflectance spectra of PYX018 and PYX020 (Figure 2) are good examples of spectral variability which can occur in compositionally similar samples (Table 1). The PYX018 spectrum exhibits a well developed type B spectrum with additional absorption bands near $0.45,0.63,0.66$, and $0.70 \mu \mathrm{m}$. These four bands can safely be ascribed to crystal field transitions in $\mathrm{Cr}^{3+}$ situated in the $\mathrm{Ml}$ crystallographic site [White et al., 1971; Hazen et al., 1978 and references therein; Khomenko and Platonoy, 1985]. PYX020 exhibits a type A spectrum with no evidence for the prominent $\mathrm{Cr}^{3+}$ absorption features in spite of a similar overall Cr content to PYX018. The only resolvable short wavelength absorption feature is a weak band present near $0.45 \mu \mathrm{m}$. This feature cannot be ascribed to $\mathrm{Cr}^{3+}$ in the $\mathrm{M} 1$ site because of the absence of the $0.63-, 0.66-$, and $0.70-\mu \mathrm{m}$ bands. The $0.45-\mu \mathrm{m}$ band in
PYX020 does not coincide with absorption bands due to $\mathrm{Cr}^{2+}$, $\mathrm{Cr}^{4+}$, or $\mathrm{Cr}^{3+}$ in a tetrahedral site [Mao et al., 1972; Burns, 1975; Schrelber, 1977, 1978; Ikeda and Yagl, 1977, 1978]. Given the low abundance or absence of other transition series elements, the likeliest candidate for this band is a spin-forbidden $\mathrm{Fe}^{2+}$ transition [Burns et al., 1972a, b, 1973; Vaughan and Burns, 1977]. Even this assignment is problematic because this absorption band is not present in all ferrous iron-bearing pyroxene spectra.

Electron microprobe examination of these two samples indicates that PYX018 contains small ( $<20 \mu \mathrm{m}$ sized) dispersed regions of a high $\mathrm{Fe} \cdot \mathrm{Cr}$, low $\mathrm{Mg}$ silicate totaling $-5 \%$ of the total sample. PYX020 does not exhibit similar regions but displays a few regions, totaling $<1 \%$ of the sample, of an iron-rich phase lining some fractures. This phase is not chromite nor is it appreciably more chromium rich than the rest of the sample. It is unknown whether the $\mathrm{Fe}-\mathrm{Cr}$ rich phase in PYX018 is responsibie for the absorption features seen in its spectrum. The fact that various cations exhibit different degrees of site preference, and the concommitant effects on ferrous iron site occupancies undoubtedly account for the variations seen in the spectra. The compositional similarities of two samples which exhibit markedly different reflectance spectra serves to emphasize the fact that cation site occupancies are one of the most important factors affecting spectral properties.

Spectral type $B$ cllnopyroxenes. Certain trends have been observed relating type $B$ spectral features to compositional variations which in some cases are contradictory. A number of clinopyroxene spectra were measured in order to augment the available spectral data and to attempt to resolve the ambiguities. Adams [1975] determined that both band I and band II minima shift to longer wavelengths with increasing calcium content and decreasing iron content. The same correlation involving iron content has also been observed in polarized absorption spectra [Burns et al., 1972b]. Hazen et al. [1978] in their study of pyroxene transmis spectra suggest that both the band I and band II absorption maxima move to longer wavelengths with both increasing calcium and iron contents. All available pyroxene spectra for which good compositional information exists have been reexamined in order to resolve this

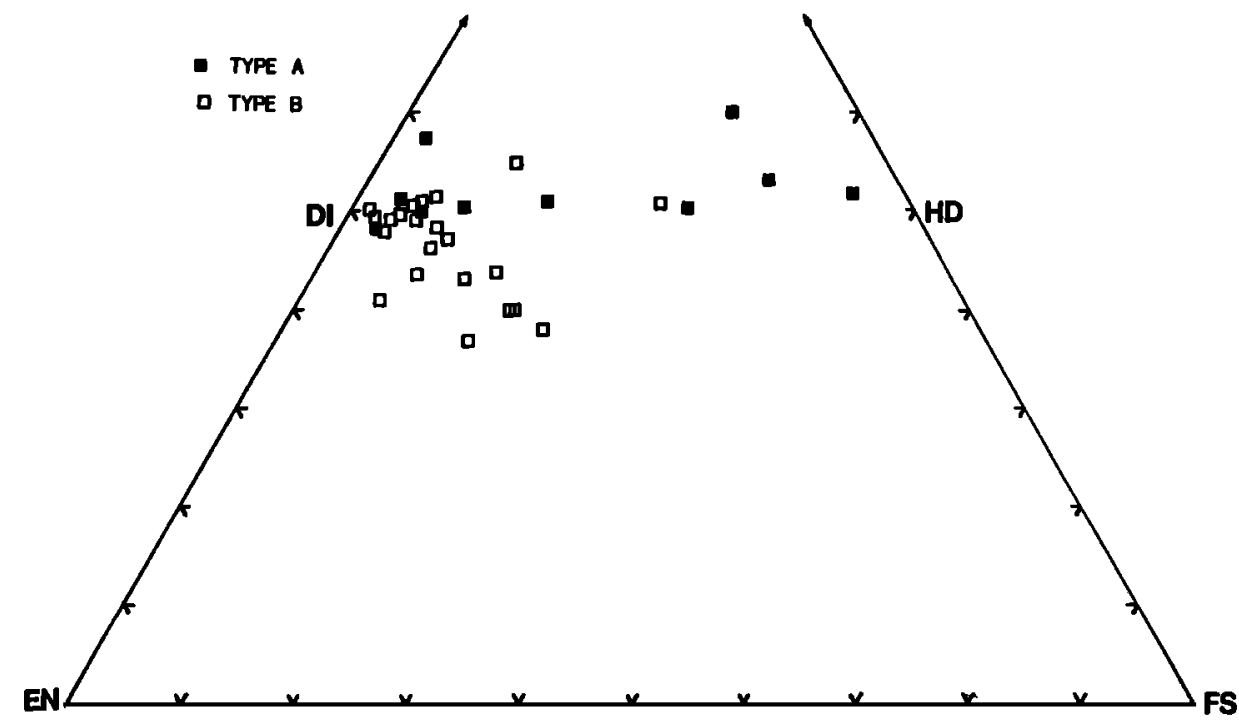

Fig. 6. Compositions of clinopyroxenes projected onto the pyroxene tetralateral illustrating the compositional distribution of spectral types $A$ and $B$. 


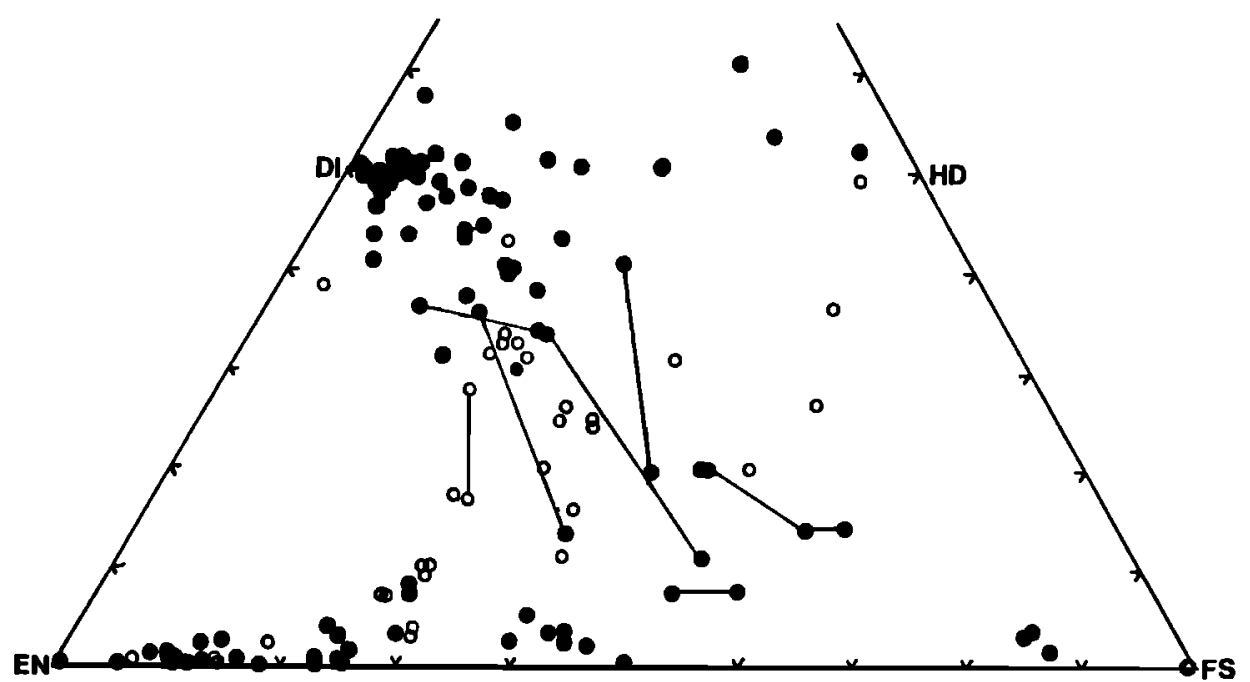

Fig. 7. Distribution of pyroxene samples for which both compositional and spectral data are available. Open symbols indicate transmission spectra, solid symbols indicate reflectance spectra. Lines connect end-member compositions of zoned or exsolved samples.

issue (Figure 7). There are obviously large regions in the pyroxene tetralateral for which very little data exists, complicating the search for compositional trends. Additional complications are introduced by the presence of samples which are strongly zoned or exsolved. Exsolved samples will exhibit reflectance spectra whose overall shapes are intermediate between the spectra of the end-members [Adans, 1974]. The spectra of strongly zoned samples will likely show broadened absorption bands due to the fact that grains of widely varying chemistry will be contributing to the reflectance spectrum. In some cases it is likely that zonations or exsolutions present in samples have not been noted.

The data relating the wavelength positions of band $I$ and band II minima to $\mathrm{Ca}$ and $\mathrm{Fe}^{2+}$ contents are illustrated in Figures 4 and 8 . The data in Figure 4 have been subdivided on the basis of $\mathrm{Ca}$ content into four ranges. Once again the data of Adams have been shifted upward by $13 \mathrm{~nm}$. Reflectance and transmittance spectra generally show the same trends. The latter are particularly useful for defining the high-iron regions of the tetralateral for which reflectance spectra are lacking. Some of the scatter in the data, particularly for intermediate calcium content samples, probably reflects zonations or exsolutions which may not be apparent or have not been documented. Although the data are somewhat limited for intermediate $\mathrm{Ca}$ content samples (11-30\% Wo) it appears that each compositional grouping is confined to a narrow wavelength interval as a function of $\mathrm{Fe}^{2+}$ content (Figure 4). There is some scatter in the data, some of which is undoubtedly associated with strongly zoned and exsolved samples.

The relationship between band position and $\mathrm{Ca}$ content is more straightforward. Positive correlations exist between $\mathrm{Ca}$ content and band position regardless of iron content (Figure 8). There is a slight suggestion of a negative correlation for $\mathrm{Ca}$ contents $>50 \mathrm{~mol} \%$, but more data are required to conf irm this trend.

Comparisons of band I minima to continuum removed band centers indicate that, on average, band centers occur at $7 \mathrm{~nm}$ above band minima; i.e., shifted to longer wavelengths by this amount. This corresponds to an overestimate of $3 \mathrm{~mol} \%$ Fs and Wo if band centers are used instead of band minima for determining composition using existing calibrations [Cloutis, 1985].

Various authors have noted that some samples tend to fall off the various trends relating spectral properties to compositional variations. Adams [1974] observed that the major absorption bands in titanium-rich augites $\left(>1 \mathrm{wt} \% \mathrm{TiO}_{2}\right)$ are shif ted to longer wavelengths relative to titanium-poor augites of comparable iron contents. He also noted that the titanium-rich augite spectra exhibit a suppressed absorption band near 0.75-0.8 $\mu \mathrm{m}$. On the basis of the expanded data set (Figures 4 and 8 ) it appears that the major absorption bands of titanium-rich pyroxenes frequently plot away from the general cluster of points for each sample subset assigned on the basis of Wo and Fs contents. The sample size is too small to determine whether there is any correlation between band positions for titanium-rich samples and the suppression of the 0.75-0.8 $\mu \mathrm{m}$ feature.

Hazen et al. [1978] found that chromium-rich diopsides (>1 wt \% $\mathrm{Cr}_{2} \mathrm{O}_{3}$ ) display their major absorption bands at higher than expected wavelengths on the basis of $\mathrm{Fe}$ and $\mathrm{Ca}$ contents. The spectral data are again limited for $\mathrm{Cr}$-rich samples, but the available samples show extreme variations in absorption band positions; they seem to be generally shifted to longer than expected wavelengths on the basis of $\mathrm{Ca}$ content and lower than expected wavelengths on the basis of $\mathrm{Fe}$ content. $\mathrm{Cr}$-diopsides of spectral type $\mathrm{B}$ can best be recognized by the presence of additional absorption bands near 0.45 and $0.65 \mu \mathrm{m}$ [Adams, 1975] which increase in intensity with increasing $\mathrm{Cr}$ content [Hazen et al., 1978]; PYX018 (Figure 2) exhibits many of these features.

Spectral type A clinopyroxenes. Determination of spectral-compositional trends for spectral type A clinopyroxenes is hampered by the fact that very few (10 samples) members of this class have been both spectrally and chemically characterized. The development of a distinct two-band structure near $1 \mu \mathrm{m}$ (due to $\mathrm{Fe}^{2+}$ in the $\mathrm{Ml}$ site) is accompanied by the almost complete disappearance of band II (due to $\mathrm{Fe}^{2+}$ in the $\mathrm{M} 2$ site) (Figure 2). By analogy to type B CPX and OPX it is expected that the two absorption bands situated near $1 \mu \mathrm{m}$ should show some sort of systematic variations as a function of major cation abundances. 

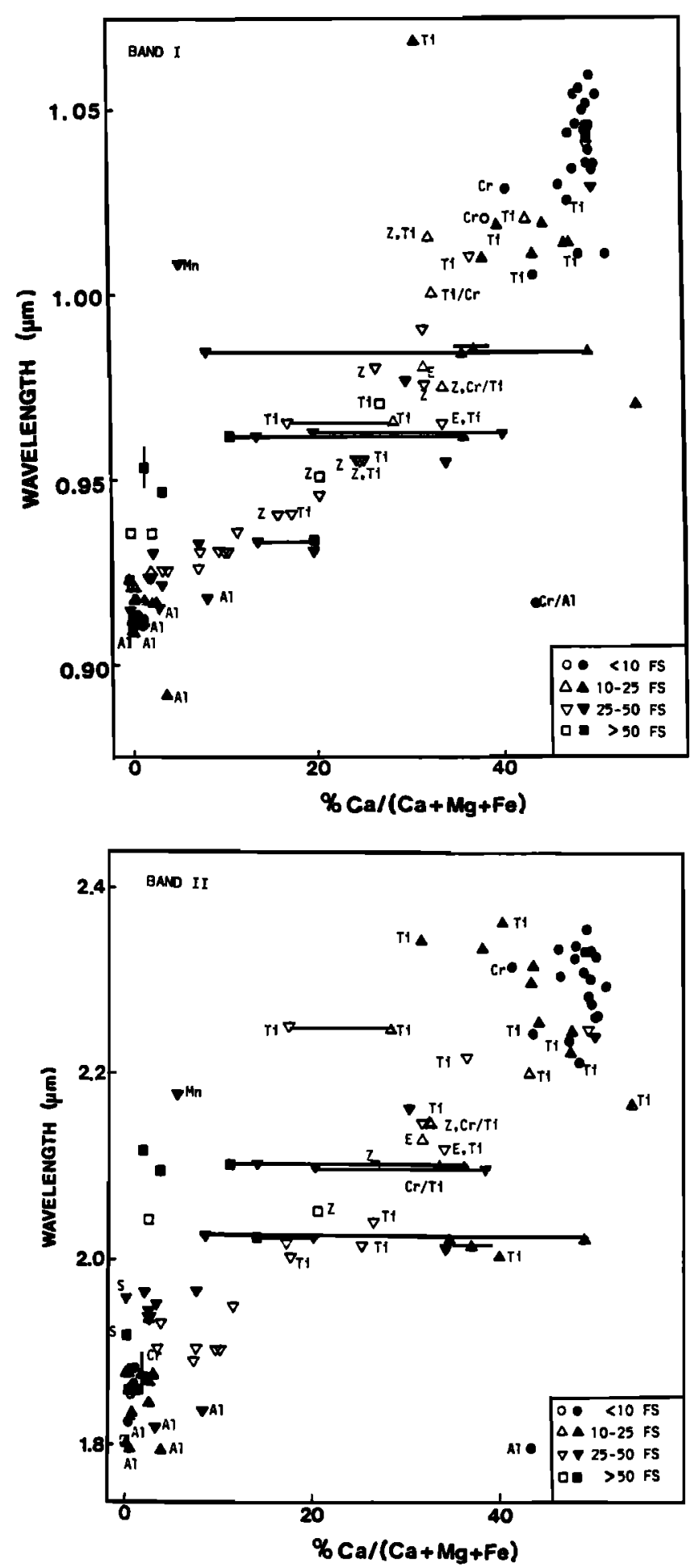

Fig. 8. Wavelength positions of (upper) band I and (lower) band II of orthopyroxenes and type B clinopyroxenes as a function of wollasonite content (i.e., $\left.\mathrm{Wo}=\mathrm{Ca} /\left(\mathrm{Ca}+\mathrm{Mg}+\mathrm{Fe}^{2+}\right)\right)$. The data have been subdivided into four groups on the basis of iron (Fs) content. Notations and sources of data are the same as for Figure 4.

Unfortunately, there appear to be no systematic relationships between $\mathrm{Fe}$ and $\mathrm{Ca}$ contents and the wavelength positions of absorption band minima (Figure 9) or separation between the two bands (Figure 10). This may be due to the nature of the reflectance spectra. Many of the spectra show very low overall reflectance and little spectral detail in the region of the absorption bands, perhaps due to charge transfers or the presence of appreciable amounts of ferric iron resulting in intense $\mathrm{Fe}^{2+}-\mathrm{Fe}^{3+}$ charge transfer absorptions. Consequently, some of the band positions can only be estimated to within $\pm-30 \mathrm{~nm}$. A larger number of spectral type A clinopyroxenes need to be characterized to establish whether spectral-compositional relationships exist.
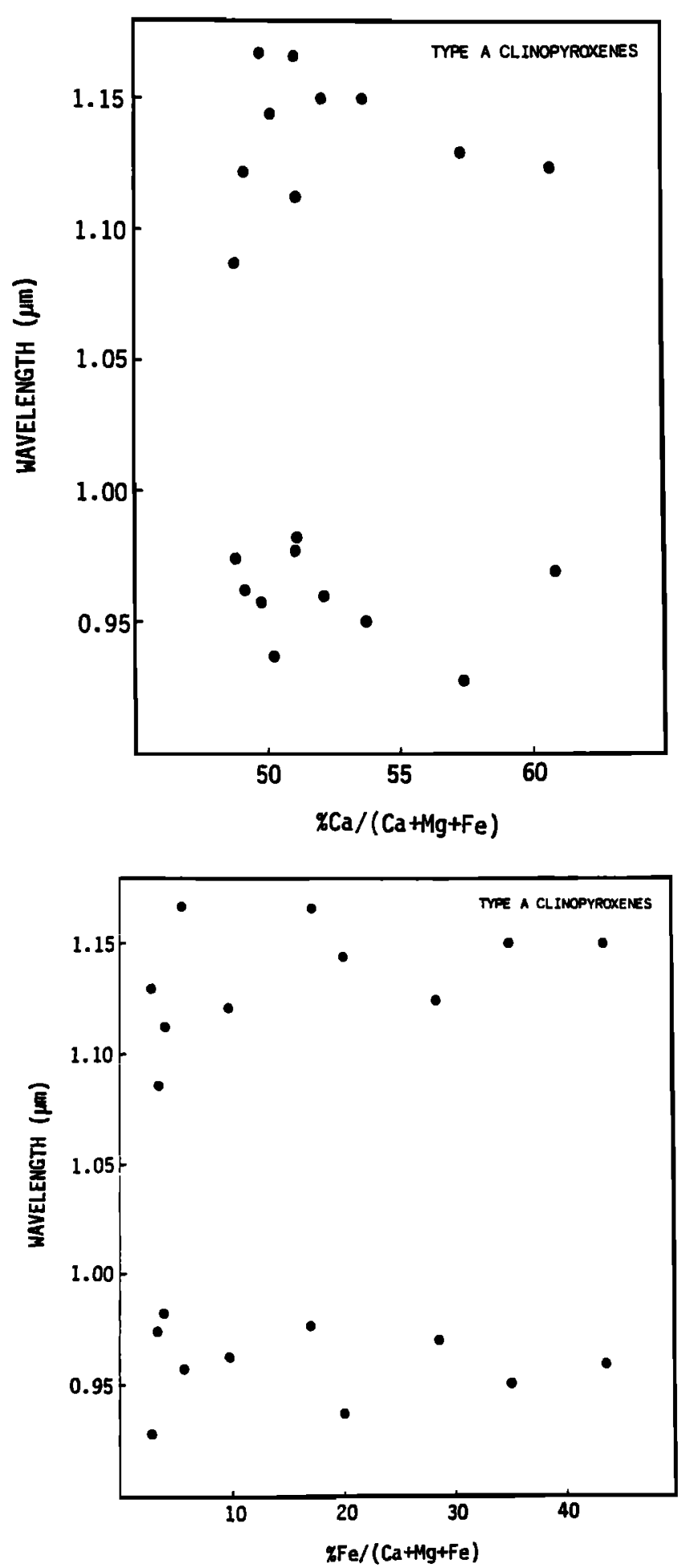

Fig. 9. (Upper) calcium and (lower) ferrous iron contents of spectral type A clinopyroxenes as a function of band minima wavelength positions for the two absorption bends situated near $1 \mu \mathrm{m}$. Absorption bands for any one sample are paired vertically. 

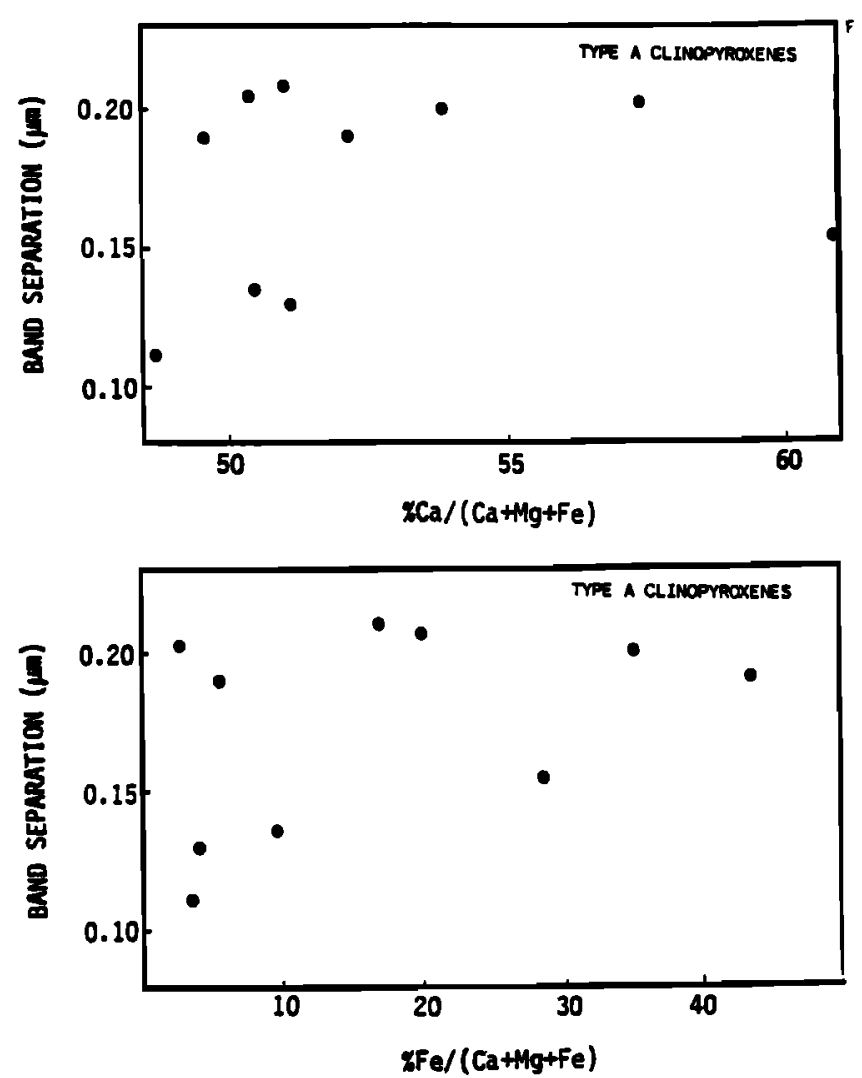

Fig. 10. (Upper) calcium and (lower) ferrous iron contents of spectral type A clinopyroxenes as a function of the separation, in microns, between the two absorption band minima situated near $1 \mathrm{\mu m}$.

\section{Heterogeneous Pyroxenes and Mixtures}

Two series of $25 \mathrm{wt} \%$ interval OPX-CPX mixtures have been spectrally characterized to augment the limited data in the literature for two-pyroxene mixtures (Figure 3). Additional mixture spectra have been measured by Adams [1974], Singer [1981], Johnson et al. [1983], and Sunshine et al. [1990]. The spectra of equal amounts of orthopyroxene and clinopyroxene show a clear dominance by the orthopyroxene in terms of overall spectral shape and absorption band positions. Clinopyroxene only begins to noticeably influence band position when its abundance approaches $75 \mathrm{wt} \%$. The relative effects of the two phases can be measured on the basis of band positions. The shift in band minima has been measured as a percentage change relative to the pure end-members (Figure 11). Each orthopyroxene-clinopyroxene series can be normalized such that the band minimum position of each clinopyroxene in a series is set to zero and each orthopyroxene to one. It is apparent from Figure 11 that orthopyroxene dominates band positions over a wide range of abundances. These systematic variations can be used to constrain the compositions of pyroxenes in two-component mixtures for pyroxenes of similar grain sizes and assuming that the end-member spectra are known. For two-pyroxene mixtures the absorption feature seen near $2 \mu \mathrm{m}$ will be some composite of the end-members, the higher wavelength band will be progressively shifted to lower wavelengths and vice versa (Figure 3 ). Thus, in a case where end-member compositions are unknown, the wavelength position of the band or bands (if two bands are resolvable) can be used to constrain end-member compositions. Curve-fitting routines are a better solution to the problem of deconvolving

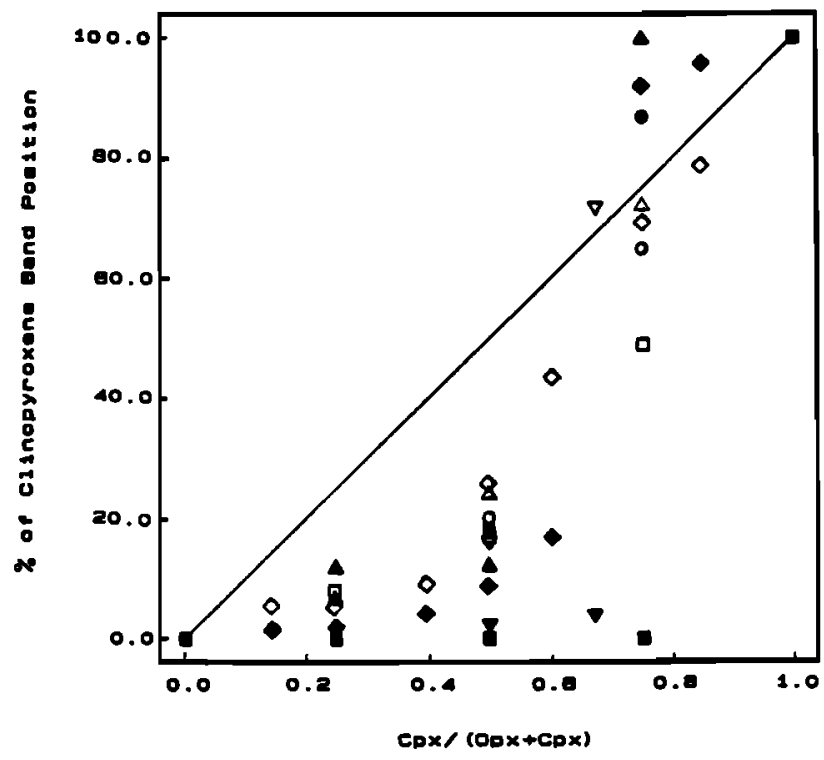

Fig. 11. Percent change in band I and band II minima wavelength positions between pure clinopyroxene and pure orthopyroxene for various OPX + CPX series. Each series is normalized such that the band minimum position of each clinopyroxene in a series is set to zero and each orthopyroxene in a series is set to one. (Open symbols) band I minima, (solid symbols) band II minima. (Squares) PYX032 + PYX040, (circles) PYX003+PYX036, (triangles) series from Singer [1981], (inverted triangles) series from Adams [1974], (diamonds) series from Sunshine et al. [1990].

pyroxene mixture spectra because the positions of the component absorption bands are invariant [Sunshine et al., 1990].

There is no consistent pattern to the wavelength positions of the absorption bands of strongly zoned or exsolved samples, the data for such samples plot both inside and outside the clusters of points for the compositional subgroups because the relative contributions of the different zones or phases are unknown (Figures 4 and 8). The reflectance spectra of two pyroxenes of intermediate composition (15-45 wt \% Wo) which have been positively identified as exhibiting strong zonation or exsolution are shown in Figure 12. Both spectra, particularly the PYX115

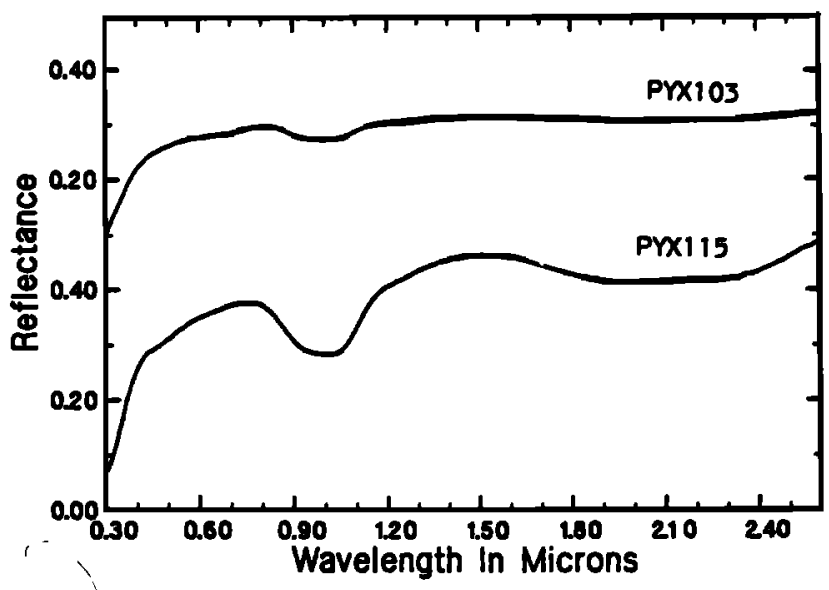

Fig. 12. Reflectance spectra of a pyroxene displaying narrow exsolution lamellae (PYX103) and a pyroxene with a range of exsolution lamellae sizes and zonations (PYX115). Both are for $<45 \mu \mathrm{m}$-sized fractions. 
spectrum, exhibit broad absorption bands in the $1-$ and $2-\mu \mathrm{m}$ regions indicative of more than one phase. Such complex spectra are also evident in the artificial two-pyroxene mixtures shown in Figure 3. Electron microprobe examination of these two pyroxenes indicates that $\mathrm{Ca}$-poor lamellae $<1 \mu \mathrm{m}$ wide in a Ca-rich host (PYX103) are sufficient to result in a reflectance spectrum exhibiting both OPX- and CPX-associated spectral features (Figure 12). PYX115 possesses narrow exsolution lamellae ( $<1 \mu \mathrm{m}$ wide) as well as much coarser exsolved phases ( $-40 \mu \mathrm{m}$ wide). Its reflectance spectrum similarly exhibits broad asymmetric absorption features (Figure 12). It would appear that the band positions and band shapes of samples containing exsolved phases will depend on the composition and relative abundances of these phases, while for zoned samples some weighted average composition will be indicated [Adams, 1974]. The former can be treated as a two-pyroxene mixture, while the latter will exhibit broadened absorption bands [Adams, 1974]. More work is required on the spectral properties of zoned and exsolved pyroxenes to better understand their spectral properties.

\section{DISCUSSION}

Orthopyroxene and type B clinopyroxene spectra are easily identified by the presence of the two absorption bands near 1 and $2 \mu \mathrm{m}$. There is no abrupt break between the wavelength positions of OPX and CPX band minima, one group blends smoothly into another and the variations in band positions seem to follow a regular pattern when plotted against each other (Figure 13), a relationship which was noted early on [Adams and McCord, 1972; Adams, 1974]. Points which deviate significantly from the general trend shown in Figure $13 \mathrm{can}$, in almost all cases, be ascribed to the presence of additional phases, extensive cation substitutions, zonations, or exsolved phases.

\section{The Pyroxene Tetralateral}

Pyroxene major element abundances $\left(\mathrm{Ca}, \mathrm{Mg}, \mathrm{Fe}^{2+}\right)$ are frequently projected onto a tetralateral to quickly highlight compositional variations [e.g., Robinson, 1980]. The data presented in Figures 4 and 8 have been combined and projected onto the pyroxene tetralateral (Figure 14). Contours of the wavelength positions of the absorption band minima have been constructed based on the combined compositional data presented in Figures 4 and 8 and are shown in Figure 15. Some uncertainties exist in the region of intermediate $\mathrm{Ca}$ content (11-30 mol \% Wo) because of concerns over the presence of undetected exsolutions or zonations which are common in this compositional range [e.g., Ghose et al., 1972; Buseck et al., 1980; Huebner, 1980; Robtnson, 1980] and the aforementioned variations due to high abundances of $\mathrm{Ti}$ and $\mathrm{Cr}$. Uncertainties are also present in the hedenbergite region of the tetralateral because of a lack of sample spectra. The contours have been constructed so as to minimize the scatter in the experimental data and to lend extra weight, where justified, to the well-characterized samples. The largest degree of scatter is present for augites because these minerals often contain appreciable amounts of other cations in addition to $\mathrm{Ca}, \mathrm{Fe}$, and Mg. It should be noted that the slope of the contours differs from those presented by Hazen et al. [1978] because the assembled data suggest that the correlation between band position and ferrous iron content is not a simple linear relationship (Figure 4). Figures 4, 8, and 15 can be used to place severe constraints on pyroxene composition, or alternatively, to predict absorption band positions from compositional information.

The contours have a generally curved shape which seems to reflect the relative influences of the iron and, indirectly, calcium. The different iron subgroups in the figures relating band position to calcium content all show generally positive

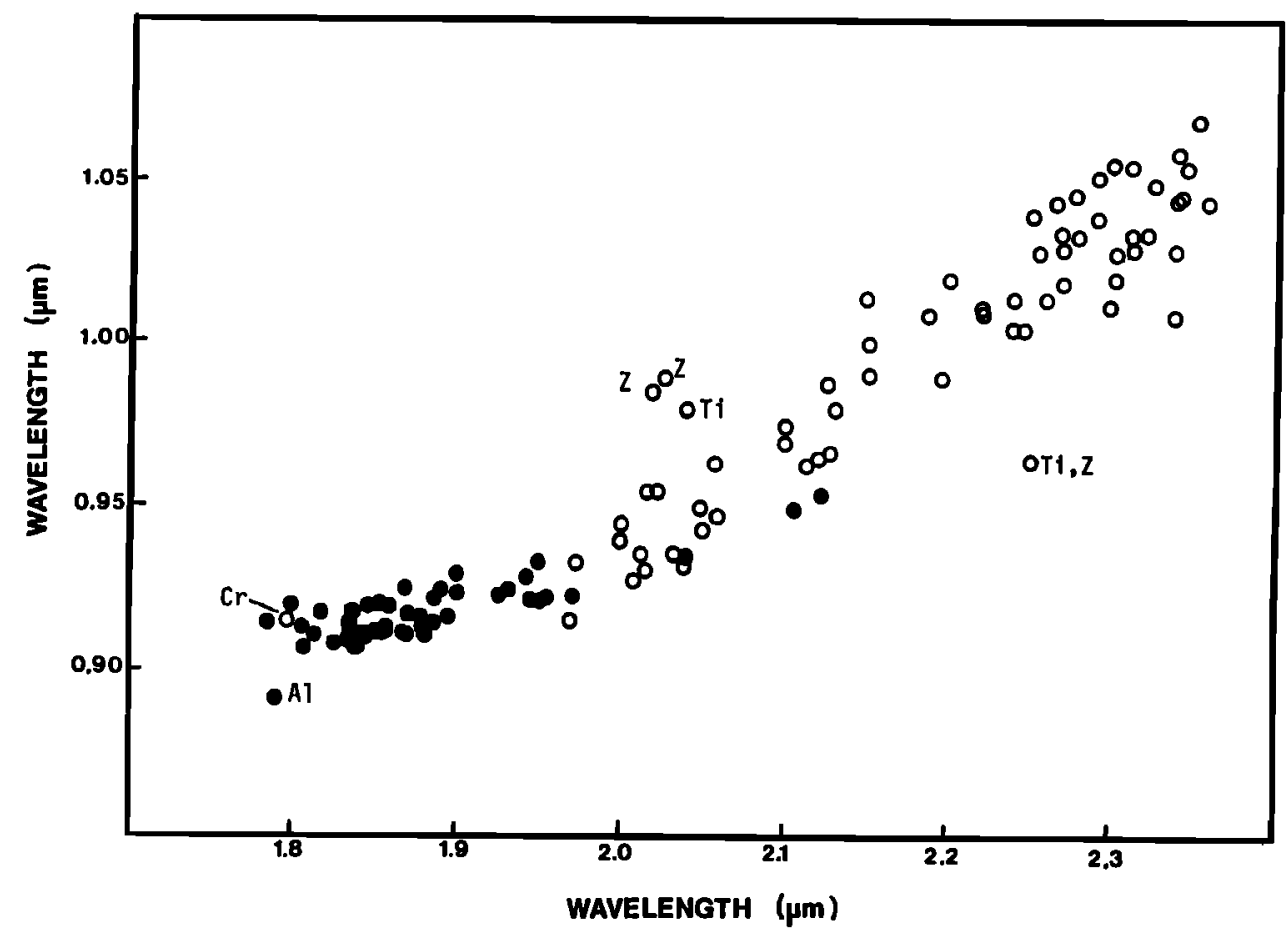

Fig. 13. An adaptation of Figure 2 from Adams (1974) showing variations in both band I and band II minima. (Solid symbols) <11 \% Wo samples, (open symbols) $>11 \%$ Wo samples. Points which deviate appreciably from this trend are invariably zoned or contain exsolved phases $(Z)$, contain $>1$ wt $\% \mathrm{TiO}_{2}\left(\mathrm{Ti}^{2}\right.$ or $\mathrm{Cr}_{2} \mathrm{O}_{3}$ $(\mathrm{Cr})$, or, in the case of low-calcium content samples, contain $>4$ wt $\% \mathrm{Al}_{2} \mathrm{O}_{3}$. Sources of data are the same as for Figure 4. 

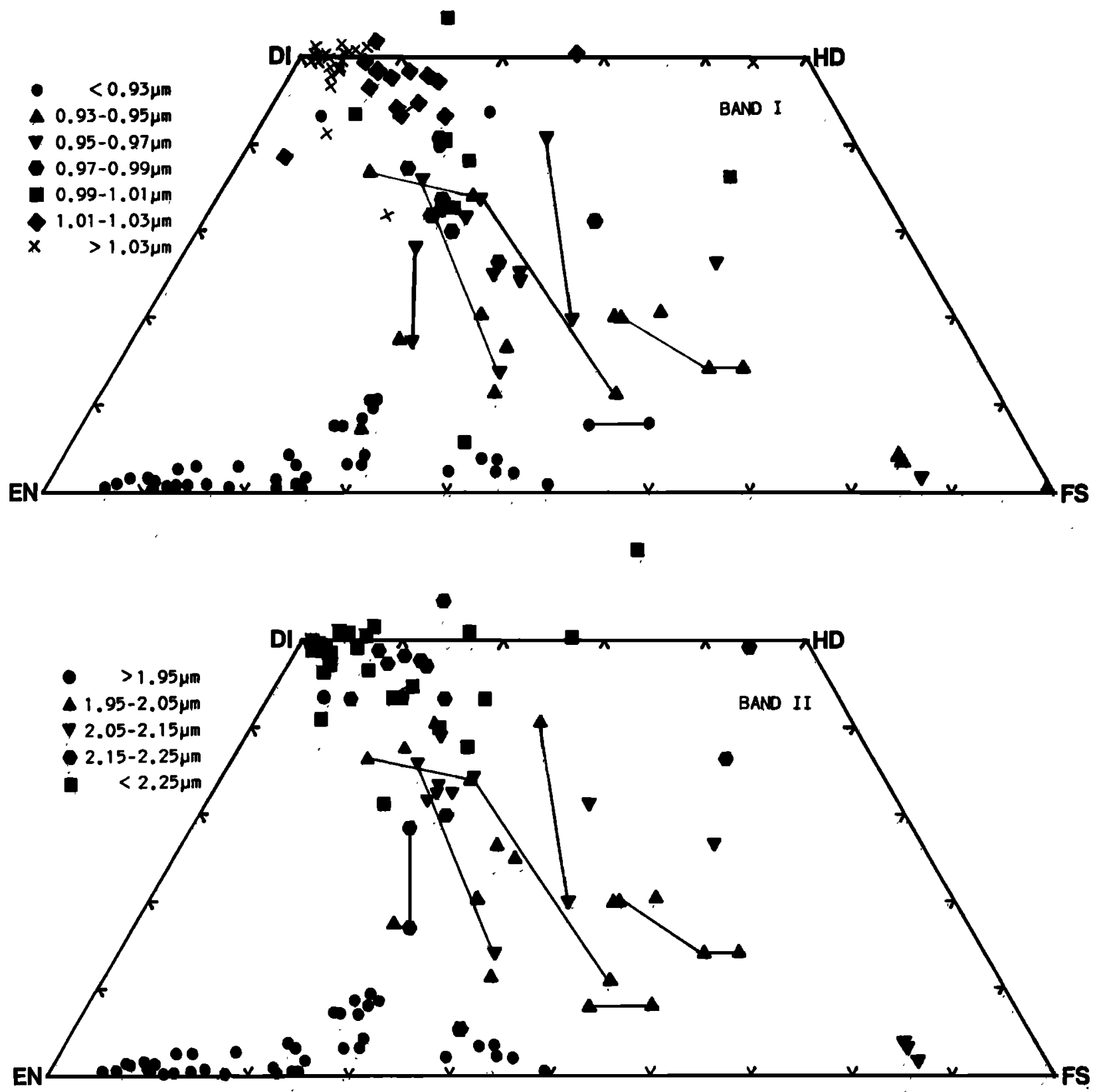

Fig. 14. Compositional distribution of pyroxenes used in this study projected onto the pyroxene tetralateral and subdivided on the basis of the wavelength positions of the major ferrous iron absorption bands present near $1 \mathrm{\mu m}$ (band I; upper) and near $2 \mu \mathrm{m}$ (band II; lower). The band positions have been binned into nartow wavelength ranges to improve clarity. Lines connect the end members of zoned or exsolved samples. Sources of data are the same as for Figure 4.

correlations (Figure 8) with the rate of increase being sensitive to the calcium content. There is too much scatter in the data to suggest that a linear relationship exists but the overall positive correlation seems inescapable. The relationship between ferrous iron content and band position is more complex (Figure 4).

Combining the various trends in the pyroxene tetralateral (Figure 14) results in the construction of contours of equal band minima position shown in Figure 14. The shapes of the contours and the separations between them 'reflect the competing effects of $\mathrm{Fe}$ and $\mathrm{Ca}$ contents on band positions. It should be noted that spectral data for the iron-rich side of the diagram are limited, therefore the contours in this region may be somewhat in error.

\section{OPX-CPX Mixtures}

It has been demonstrated that $\mathrm{OPX}$ is a more intense absorber than CPX for a given ferrous iron content (Figure 3). This is also evidenced by the fact that bend positions are more strongly influenced by orthopyroxene rather than clinopyroxene. On Figure 11 the normalized band positions for $50 / 50$ OPX/CPX mixtures are skevied toward the orthopyroxene end members. Low abundances of CPX in a mixture are harder to detect than low abundances of OPX. The combination of the OPX and CPX bands results in overall aborption features whose wayelength positions are intermediate between the two end members [Adans, 1974; Singer, 1981; Clouts, 1985]. These complex absorption features can be used to constrain the end 

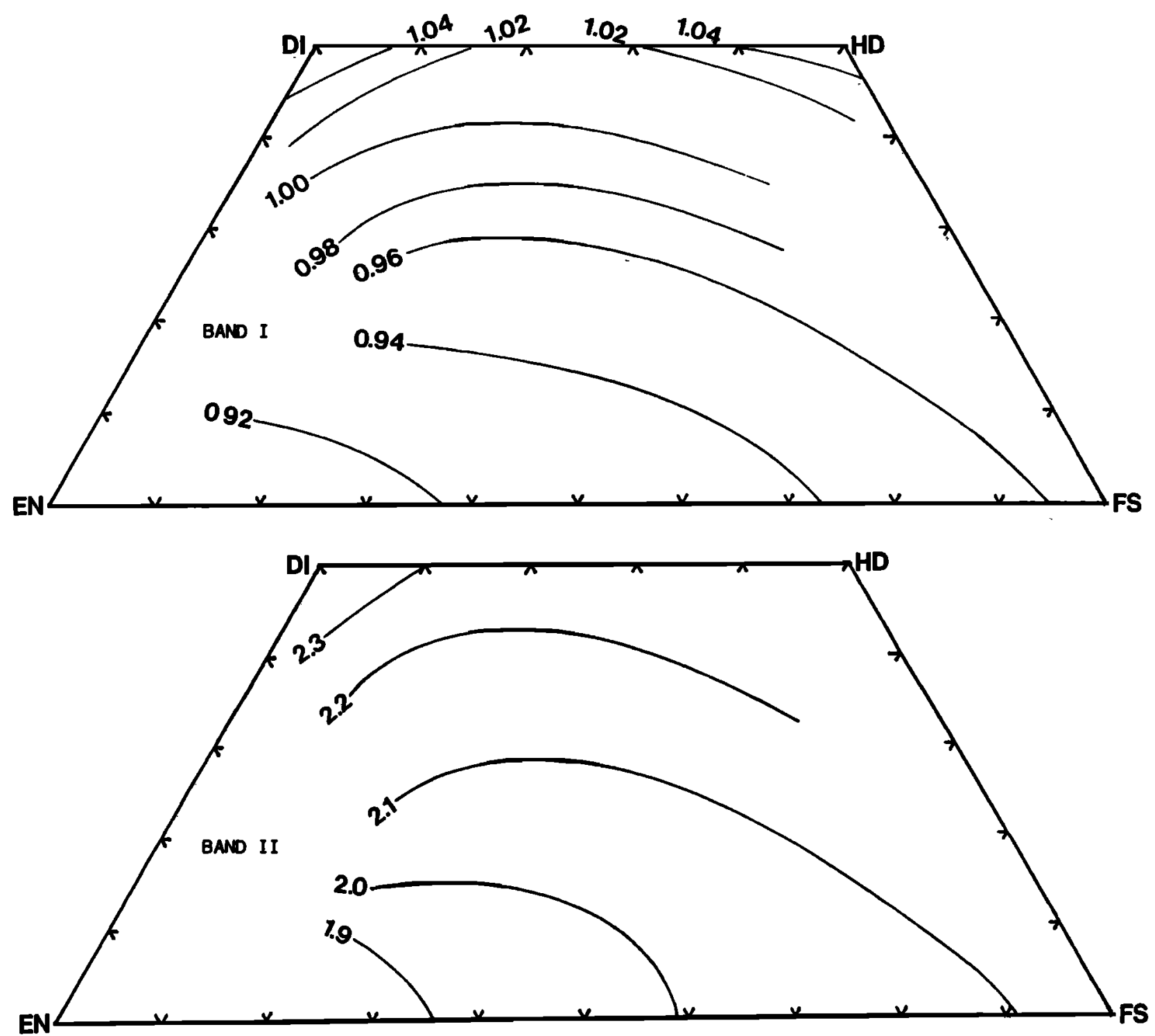

Fig. 15. Pyroxene tetralateral with contours of (upper) band I minima and (lower) band II minima wavelength positions shown. Contours have been terminated where no sample spectra are available.

member compositions and abundances even in the absence of more sophisticated spectral analysis techniques, such as radiative transfer theory [Hapke, 1981], derivative spectroscopy [Huguenin and Jones, 1986], or curve fitting [Sunshine et al., 1990], particularly if equilibrium OPX-CPX assemblages are assumed, as the partitioning of major cations between the two phases has been extensively documented [e.g., Ramberg and DeVore, 1951; Kell and Fredrtksson, 1964; Huebner, 1980; Prinz et al., 1983].

Some form of curve fitting of fers the greatest promise for deconvolving $\mathrm{OPX}+\mathrm{CPX}$ spectra since the wavelength positions of the constituent pyroxene bands are invariant [Sunshine et al., 1990]. The overlap among the orthopyroxene and clinopyroxene absorption bands in the $2-\mu \mathrm{m}$ region causes both the band II minima to appear at wavelengths intermediate between the pure end-members, and use of these band II minima may only provide broad constraints on pyroxene compositions. Use of various spectral analysis techniques such as those mentioned above should facilitate the determination of the band positions of the end-members.

\section{Spectroscoptc Geothermometry}

If pyroxenes are present on the surface of a body for which spectroscopic data are available or obtainable, it should theoretically be possible to constrain the thermal history of the body through remote sensing means. Pyroxene abundances on the order of a few weight percent are potentially detectable on planetary surfaces although this detection limit depends on the nature of the accessory phases present [Cloutls et al., 1990a, b].

OPX-CPX compositional relationships have been used to produce geothermometers based on partitioning of $\mathrm{Ca}, \mathrm{Mg}$, and $\mathrm{Fe}^{2+}$ between the two phases [Wood and Banno, 1973; Wells, 1977; Kretz, 1982; Lindsley, 1983; Lindsley and Andersen. 1983]. Geothermometers based on the partitioning of the major elements should theoretically be amenable to analysis by spectroscopic remote sensing because the spectral analysis techniques outlined above are most sensitive to major cation abundances. The various pyroxene thermometers are based on extensive experimental and observational data. The large number of possible elemental substitutions, particularly for 
clinopyroxenes, necessarily limits the practical accuracy of these thermometers to a few tens of degrees at best.

Geotherms $\left(200^{\circ} \mathrm{C}\right.$ intervals) determined by Lindsley [1983] have been overlain with the contours of band minima positions previously determined (Figure 16). The separation between the geotherms is greater for CPX than OPX which immediately introduces a greater uncertainty in using OPX rather than CPX geotherms if all other factors are equal. The uncertainties in pyroxene absorption band position can be translated into uncertainties in derived temperatures. As mentioned, the discrepancy between band centers and band minima is $-7 \mathrm{~nm}$. Use of centers rather than minima in Figures 15 and 16 would introduce an overestimate of $-3 \%$ Fs and Wo. This potential source of error can be minimized by applying an appropriate shift to bend center data or by using band minima.

The amount of scatter in the spectral data used to construct the band minima position contours depends on the location in the tetralateral. This will subsequently affect the accuracy of any derived temperatures. Average variations are on the order of $\pm 2-3 \%$ Wo and $F s$ in the diopside region of the tetralateral and increase to $\pm 4-7 \%$ Wo and Fs in the $10.45 \%$ Wo region.
For orthopyroxenes the variations are on the order of $\pm 1-2 \%$ Wo and \pm 5-10\% Fs. The variations are generally greater for titanium-rich augites and chromium-rich diopsides, which can often be recognized by the presence of other spectral properties, and for aluminous orthopyroxenes, which cannot be unambiguously identified at present.

By far the largest source of uncertainty in routinely applying spectroscopy to deriving thermometric information stems from the orientation of the band position contours relative to the geotherms. Both the band I and band II contours have approximately the same shapes and are roughly orthogonal to the geotherms. Since the contours straddle a range of geotherms, instead of paralleling them, at best only a range of possible temperatures can be specified. Most of the band position contours cross over all the geotherms shown, spanning the entire temperature range under consideration $\left(600^{\circ}-1200^{\circ} \mathrm{C}\right)$. Therefore band minima data alone are insufficient to provide even the most minimal constraints on temperatures of formations of pyroxenes in the vast majority of cases. Additional spectral parameters which can account for the presence of commonly occuring transition series elements such as
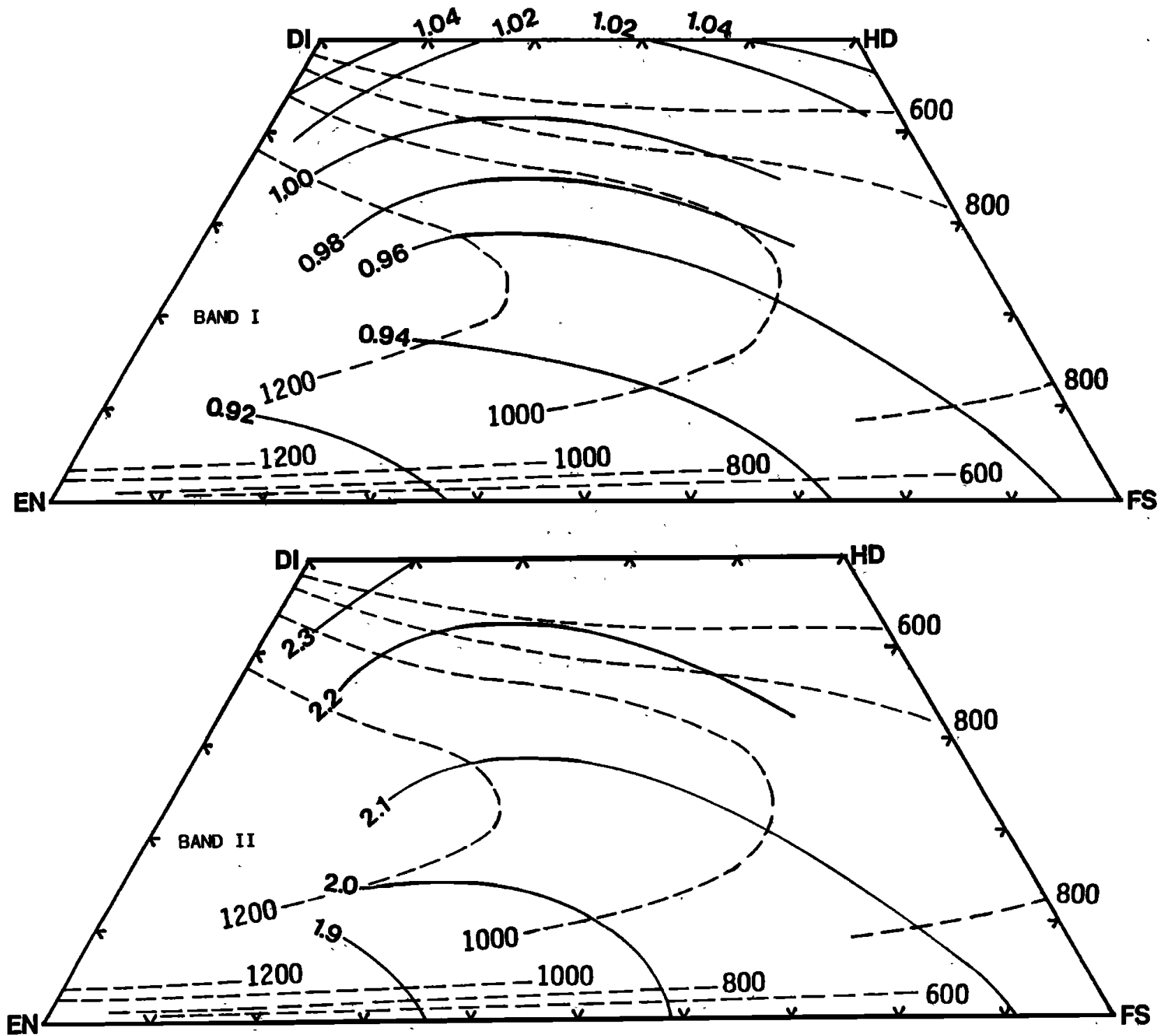

Fig. 16. Same as Figure 14 with $200^{\circ} \mathrm{C}$ interval geotherms from Lindsley [1983] overlain. The geotherms are for 1 atmosphere pressure. Band contours and geotherms are generally orthogonal. 
$\mathrm{Cr}$ and $\mathrm{Ti}$, or spectral parameters that can be projected onto the pyroxene tetralateral, which roughly parallel the geotherms, and which can constrain pyroxene composition, must be developed if spectroscopy is to have any practical applications to pyroxene geothermometry.

\section{CONCLUSIONS}

The spectral reflectance properties of pyroxenes have been reexamined in order to better understand the mechanisms controlling absorption band variations, to clear up ambiguities in spectral-compositional relationships, to increase the amount and quality of data available for two-pyroxene mixtures, and to examine the potential applications of reflectance spectroscopy to pyroxene geothermometry.

The two major absorption bands seen in orthopyroxene spectra in the 0.3-2.6 $\mu \mathrm{m}$ wavelength range which are due to crystal field transitions in $\mathrm{Fe}^{2+}$ both move to longer wavelengths with increasing ferrous iron content. This relationship is valid for Wo abundances up to $-11 \%$. Greater abundances of Wo produce spectral effects which more closely resemble clinopyroxenes. Aluminum-rich orthopyroxenes ( $>4$ wt \% $\mathrm{Al}_{2} \mathrm{O}_{3}$ ) were first recognized by Adams [1974] as exhibiting anomalous spectral behavior. The available data suggest that every 1 wt \% increase in $\mathrm{Al}_{2} \mathrm{O}_{3}$ content is spectrally equivalent to a $5 \%$ decrease in Fs content [Cloutis et al., 1990a]. As yet, no consistent spectral parameter has been found to identify aluminum-rich orthopyroxenes. Mean grain sizes of orthopyroxenes are difficult to constrain in the absence of absolute reflectance information.

Clinopyroxene spectra are of two main types, A and B. Type B spectra are superficially similar to orthopyroxene spectra, in that they exhibit absorption bands near $1 \mu \mathrm{m}$ (band I) and 2 $\mu \mathrm{m}$ (band II). Clinopyroxenes exhibiting type A spectra are generally confined to samples containing $>50 \%$ Wo, but overall composition alone is not sufficient to determine whether a clinopyroxene will exhibit a type $A$ or type B spectrum. The primary factor controlling clinopyroxene spectral shape (type $A$ versus type B) is ferrous iron site occupancies. Additional analytical techniques such as Mossbauer spectroscopy may be required to ascertain ferrous iron site occupancies and to relate them to the spectral features observed. Few spectral type $A$ clinopyroxenes have been studied. It appears that the majority of them contain $>-50 \%$ Wo. The limited quality and quantity of the spectral data preclude the establishment of definitive spectral-compositional trends.

Relationships between major cation abundances and the wavelength positions of band minima have been the subject of some controversy. This is partially due to the discrepancies between the data of Adams $[1974,1975]$ and other investigators as previously detailed. The available spectral data indicate somewhat more complex relationships than simple linear correlations. Deriving these relationships is hindered by the quality and quantity of the spectral data and by the presence of various cation substitutions, primarily involving transition series elements, which are particularly prevalent in augites and to a lesser extent in diopsides. Further complications arise due to the presence of additional (exsolved) phases and compositional zonations. Even small-scale compositional variations in the form of narrow $(<1 \mu \mathrm{m})$ exsolution lamellae are sufficient to affect spectral properties. Titanium-rich augites and chromium-rich diopsides show the largest deviations from the derived trends (e.8., Figures 8 and 13) but these samples can usually be recognized on the basis of other spectral criteria. These include the lack of an absorption band in the 0.75-0.8 $\mu \mathrm{m}$ region for titanium-rich augites and for chromium-rich diopsides the presence of additional absorption bands in the visible region [Adams, 1974; Hazen et al., 1978].

The spectra of orthopytoxene + clinopyroxene mixtures indicate that orthopyroxene is a more spectrally dominant phase. A modified Gaussian model of pyroxene absorption bands [Sunshine et al., 1990] is most useful for deconvolving mixture spectra into component parts, yielding both compositional and abundance information.

The wavelength positions of pyroxene absorption band minima projected onto the pyroxene tetralateral show more complex variations as a function of composition than previously believed. Contours of equal band position can serve to constrain pyroxene composition. High-calcium content samples can quickly be differentiated from low-calcium content ones. Geotherms [Llndsley, 1983] projected onto the pyroxene tetralateral are roughly orthogonal to band position contours. Therefore temperatures of formation cannot be effectively constrained by spectral techniques based on the wavelength positions of major absorption band minima or centers which have been found to be the most sensitive indicators of major cation abundances.

Acknowledgments. The authors wish to thank the various agencies which have provided the necessary support for this project including grants-in-aid of research from Sigma $X i$, The Scientific Research Society (to E.A.C.), the Geological Society of America grant 3741-87 (to E.A.C.), and NASA Planetary Geology and Geophysics grant NAGW 642 (to M.J.G.). The authors also wish to thank E. D. Ghent and John Machacek of the University of Calgary electron microprobe facility and Alex Stelmach of the University of Alberta for their kind assistance in characterizing the various specimens, Carle Pieters and Stephen Pratt of Brown University for generously providing ready access to the NASA RELAB spectrometer facility, and John Sampson-White and Pete Dunn of the Smithsonian Institution for making available a number of pyroxene samples. Thanks also to Marcie Nelson and an anonymous reviewer for the many helpful comments and suggestions which served to greatly improve the readability of the paper and reduce the ambiguities which inevitably arose.

\section{REFERENCES}

Adams, J. B., Visible and near-infrared diffuse reflectance spectra of pyroxenes as applied to remote sensing of solid objects in the solar system, J. Geophys. Res., 79, 4829-4836, 1974.

Adams, J. B., Interpretation of visible and near-infrared diffuse reflectance spectra of pyroxenes and other rock-forming minerals, in Infrared and Raman Spectrosocpy of Lunar and Terrestrial Minerals, edited by C. Karr Jr., pp. 91-116, Academic, San Diego, Calif., 1975.

Adams, J. B., and A. L. Filice, Spectral reflectance 0.4 to 2.0 microns of silicate rock powders, J. Geophys. Res., 72, 5705-5715, 1967.

Adams, J. B., and T. B. McCord, Electronic spectra of pyroxenes and interpretation of telescopic spectral reflectivity curves of the moon, Proc. Lunar Scl. Conf., 3rd, 3021-3034, 1972.

Aoyama, T., T. Hiroi, M. Miyamoto, and H. Takeda, Absorption spectra and bulk chemical compositions of achondritic polymict breccias with reference to characterization of the surface of Vesta-like asteroids (abstract), Lunar Planet. Scl. Conf., XVIII, 27-28, 1987. 
Bancroft, G. M., and R. G. Burns, Interpretation of the electronic spectra of iron in pyroxenes, Am. Mineral., 52 , 1278-1287, 1967.

Bancroft, G. M., A. G. Meddock, and R. G. Burns, Application of the Mossbauer effect to silicate mineralogy, I, Iron silicates of known crystal structure, Geochim. Cosmochlm. Acte, 31, 2219-2246, 1967.

Basaltic Volcanism Study Project, Basaltic Volcanism on the Terrestrlal Planets, Pergamon, New York, 1981.

Bell, P. M., and H. K. Mao, Crystal-field studies of lunar samples, Year Book Carnegie Inst. Washington, 71, 480-489, 1972.

Burns, R. G., Mineralogical Applications of Crystal Field Theory, Cambridge University Press, New York, 1970.

Burns, R. G., On the occurrence and stability of divalent chromium in olivines included in diamonds, Contrib. Mineral. Petrol., 51, 213-221, 1975.

Burns, R. G., F. E. Huggins, and R. M. Abu-Eid, Polarized absorption spectra of single crystals of lunar pyroxenes and olivines, Moon, 4, 93-102, $1972 a$.

Burns, R. G., R. Abu-Eid, and F. E. Huggins, Crystal field spectra of lunar pyroxenes, Proc. Lunar Sci. Conf., 3rd, 533-543, $1972 b$.

Burns, R. G., D. J. Vaughan, R. M. Abu-Eid, and M. Witner, Spectral evidence for $\mathrm{Cr}^{3+}, \mathrm{Ti}^{3+}$, and $\mathrm{Fe}^{2+}$ rather than $\mathrm{Cr}^{2+}$ and $\mathrm{Fe}^{3+}$ in lunat ferromagnesian silicates, Proc. Lunar Scl. Conf., 4th, 983-994, 1973.

Buseck, P. R., G. L. Nord Jr., and D. R. Veblen, Subsolidus phenomena in pyroxenes, in Reviews in Mineralogy, vol. 7, Pyroxenes, edited by C. T. Prewitt, pp. 117-211, Mineralogical Society of America, Washington, D. C., 1980.

Cameron, M., and J. J. Papike, Crystal chemistry of silicate pyroxenes, in Reviews in Mineralogy, vol. 7, Pyroxenes, edited by C. T. Prewitt, pp. 5-92, Mineralogical Society of America, Washington, D. C., 1980.

Clark, R. N., A large-scale interactive one dimensional array processing system, Publ. Astron. Soc. Pac., 92, 221-224, 1980.

Clark, S. P., Jr., Absorption spectra of some silicates in the visible and near infrared, Am. Mineral., 42, 732-742, 1957.

Cloutis, E. A., Interpretive techniques for reflectance spectra of mafic silicates, M.S. thesis, Univ. of Hawaii, Honolulu, 1985.

Cloutis, E. A., M. J. Gaffey, T. L. Jackowski, and K. L. Reed, Calibrations of phase abundance, composition, and particle size distribution for olivine-orthopyroxene mixtures from reflectance spectra, J. Geophys. Res., 91, $11,641-11,653,1986$.

Cloutis, E. A., M. J. Gaffey, D. G. W. Smith, and R. St J. Lambert, Metal-silicate mixtures: Spectral properties and applications to asteroid taxonomy, J. Geophys. Res., 95, 8323-8338, 1990a.

Cloutis, E. A., M. J. Gaffey, D. G. W. Smith, and R. St J. Lambert, Reflectance spectra of mafic silicate-opaque assemblages with applications to meteorite spectra, Icarus, 84, 315-333, 19906.

Cruikshank, D. P., D. J. Tholen, W. K. Hartmann, J. F. Bell, and $R$. H. Brown, Three basaltic earth-approaching asteroids and the source of the basaltic meteorites, Icarus, 89, 1-13, 1991.

Dodd, R. T., Meteorites: A Chemical-Petrologic Synthesis, Cambridge University Press, New York, 1981.

Feierberg, M. A., H. P. Larson, U. Fink, and H. A. Smith, Spectroscopic evidence for 2 achondrite parent bodies: Aste- roids 349 Dembowska and 4 Vesta, Geochlm. Cosmochim. Acta, 44, 513-524, 1980.

Gaffey, M. J., Spectral reflectance characteristics of the meteorite classes, J. Geophys. Res., 81, 905-920, 1976.

Ghose, S., $\mathrm{Mg}^{2+}-\mathrm{Fe}^{2+}$ order in an orthopyroxene $\mathrm{MBO}_{3} \mathrm{Fe}_{10}, \mathrm{Si}_{2} \mathrm{O}_{6}$, Zelt. Krist., 122, 81-99, 1965.

Ghose, S., G. NG, and L. S. Walter, Clinopyroxenes from Apollo 12 and 14: Exsolution, domain structure, and cation order, Proc. Lunar Scl. Conf., 3rd, 507-531, 1972.

Hapke, B., Bidirectional reflectance spectroscopy, 1, Theory, $J$. Geophys. Res., 86, 3039-3054, 1981.

Hazen, R. M., P. M. Bell, and H. K. Mao, Effects of compositional variation on absorption spectra of lunar pyroxenes, Proc. Lunar Scl. Conf., 9th, 2919-2934, 1978.

Huebner, J. S., Pyroxene phase equilibria at low pressure, in Reviews In Mineralogy, vol. 7, Pyroxenes, edited by C. T. Prewitt, pp. 213-288, Mineralogical Society of America, Washington, D. C., 1980.

Huguenin, R. L., The silicate component of Martian dust, Icarus, 70, 162-188, 1987.

Huguenin, R. L., and J. L. Jones, Intelligent information extraction from reflectance spectra: Absorption band positions, J. Geophys. Res., 91, 9585-9598, 1986.

Hunt, G. R., and J. W. Salisbury, Visible and near-infrared spectra of minerals and rocks: I. Silicate minerals, Mod. Geol., 1, 283-300, 1970.

Ikeda, K., and K. Yagi, Experimental study on the phase equilibria in the join $\mathrm{CaMgSi}_{2} \mathrm{O}_{6}-\mathrm{CaCrSi}_{2} \mathrm{O}_{6}$ with special ref erence to the blue diopside, Contrlb. Mineral. Petrol., 61, 91-106, 1977.

Ikeda, K., and K. Yagi, Reply to H. D. Schreiber, Contrlb. Mineral. Petrol., 66, 343-344, 1978.

Johnson, P. E., M. O. Smith, S. Taylor-George, and J. B. Adams, A semiempirical method for analysis of the reflectance spectra of binary mineral mixtures, J. Geophys. Res., 88, 3557-3561, 1983.

Keil, K., and K. Fredriksson, The iron, magnesium, and calcium distribution in coexisting olivines and rhombic pyroxenes of chondrites, J. Geophys. Res., 69, 3487-3515, 1964.

Khomenko, V. M., and A. N. Platonov, Electronic absorption spectra of $\mathrm{Cr}^{3+}$ ions in natural clinopyroxenes, Phys. Chem. Minerals, 11, 261-265, 1985.

Kretz, R., Transfer and exchange equilibria in a portion of the pyroxene quadrilateral as deduced from natural and experimental data, Geochtm. Cosmochim. Acta, 46, 411-421, 1982.

Lindsley, D. H., Pyroxene thermometry, Am. Mineral., 68, 477-493, 1983.

Lindsley, D. H., and D. J. Andersen, A two-pyroxene thermometer, Proc. Lunar Planet. Scl. Conf., 13th, Part 2, J. Geophys. Res., 88, suppl., A887-A906, 1983.

Mao, H. K., P. M. Bell, and J. S. Dickey Jr., Comparison of the crystal-field spectra of natural and synthetic chrome diopside, Year Book Carnegle Inst. Washington, 71, 538-541, 1972.

McCord, T. B., and R. N. Clark, The Mercury soil: Presence of $\mathrm{Fe}^{2+}$, J. Geophys. Res., 84, 7664-7668, 1979.

McCord, T. B., J. B. Adams, and T. V. Johnson, Asteroid Vesta: Spectral reflectivity and compositional implications, Science, 168, 1445-1447, 1970.

McFadden, L. A., M. J. Gaffey, H. Takeda, T. L. Jackowski, and K. L. Reed, Reflectance spectroscopy of diogenite meteorite types from Antarctica and their relationship to 
asteroids, Proceedings of Seventh Symposium on Antarctic Meteorites, Mem. Natl. Inst. Polar Res. Spec. Issue, 25, 188-206, 1982.

Morimoto, N., J. Fabries, A. K. Ferguson, I. V. Ginsburg, M. Ross, F. A. Seifert, J. Zussman, K. Aoki, and G. Gottardi, Nomenclature of pyroxenes, Am. Mineral., 73, 1123-1133, 1988.

Nash, D. B., and J. E. Conel, Spectral reflectance systematics for mixtures of powdered hypersthene, labradorite and ilmenite, J. Geophys. Res., 79, 1615-1621, 1974.

Pieters, C. M., Polarization in a mineral absorption band, in Planets, Stars and Nebulae Studled with Photopolartmetry, edited by T. Gehrels, pp. 405-418, University of Arizona Press, Tucson, 1974.

Pieters, C. M., Strength of mineral absorption features in the transmitted component of near-infrared light: First results from RELAB, J. Geophys. Res., 88, 9534-9544, 1983.

Prinz, M., C. E. Nehru, J. S. Delaney, and M. Weisberg, Silicates in $\mathrm{IAB}$ and IIICD irons, winonaites, lodranites and brachina: A primitive and modified primitive group (abstract), Luner Planet. Scl. Conf., XI, 616-617, 1983.

Ramberg, H., and G. DeVore, The distribution of $\mathrm{Fe}^{+*}$ and $\mathrm{Mg}^{++}$in coexisting olivines and pyroxenes, J. Geol., 59, 193-210, 1951.

Robinson, P., The composition space of terrestrial pyroxenesInternal and external limits, in Reviews in Mineralogy, vol. 7. Pyroxenes, edited by C. T. Prewitt, pp. 419-494, Mineralogical Society of America, Washington, D. C., 1980.

Rossman, G. R., Optical absorption spectra of major minerals in Luna 24 sample 24170, in Papers Presented to the Conference on Lune 24, pp. 156-159, Lunar Science Institute, Houston, 1977.

Rossman, G. R., Pyroxene spectroscopy, in Revlews in Mineralogy, vol. 7, Pyroxenes, edited by C. T. Prewitt, pp. 93-116, Mineralogical Society of America, Washington, D.C., 1980.

Roush, T. L., Effects of temperature on remotely sensed mafic mineral absorption features, M.S. thesis, Univ. of Hawaii, Honolulu, 1984.

Runciman, W. A., D. Sengupta, and M. Marshall, The polarized spectra of iron in silicates, I, Enstatite, Am. Mineral., 58, 444-450, 1973.

Schreiber, H. D., On the nature of synthetic blue diopside crystals: The stabilization of tetravalent chromium, $\mathrm{Am}$. Mineral., 62, 522-527, 1977.

Schreiber, H. D., Chromium, blue diopside, and experimental petrology, Contrib. Mineral. Petrol., 66, 341-342, 1978.

Singer, R. B., Near-infrared spectral reflectance of mineral mixtures: Systematic combinations of pyroxenes, olivine and iron oxides, J. Geophys. Res., 86, 7967-7982, 1981.

Singer, R. B., J. S. Miller, K. W. Wells, and E. S. Bus, Visible and near-IR spectral imaging of Mars during the 1988 opposition (abstract), Lunar Planet. Sct. Conf., XXI, 1164-1165, 1990.

Sunshine, J. M., C. M. Pieters, and S. F. Pratt, Deconvolution of mineral absorption bands: An improved approach, $J$. Geophys. Res., 95, 6955-6966, 1990.

Surkov, Y. A., L. P. Moskalyeva, O. P. Shcheglov, V. P. Kharyukovo, O. S. Manvelyan, V. S. Kirichenko, and A. D. Dudin, Determination of the elemental composition of rocks on Venus by Venera 13 and Venera 14 (Preliminary results), Proc. Lunar Planet. Sct. Conf., 13th, Part 1, J. Geophys. Res., 88, suppl., A481-A492, 1983.

Vaughan, D. J., and R. G. Burns, Electronic absorption spectra of lunar minerals, Phllos. Trans. R. Soc. London Ser. A, 285, 249-258, 1977.

Warren, B. E., and W. L. Bragg, The structure of diopside $\mathrm{CaMg}\left(\mathrm{SiO}_{3}\right)_{2}$, Zelt. Krist., 69, 168-193, 1929.

Weidner, V. R., and J. J. Hsia, Reflection properties of pressed polytetrafluoroethylene powder, J. Opt. Soc. Am., 71, 856-861, 1981.

Wells, P. R. A., Pyroxene thermometry in simple and complex systems, Contrlb. Mneral. Petrol., 62, 129-139, 1977.

White, W. B., and K. L. Keester, Optical absorption spectra of iron in the rock forming silicates, Am. Mneral., 51 , 774-791, 1966.

White, W. B., G. J. McCarthy, and B. E. Scheetz, Optical spectra of chromium, nickel, and cobalt-containing pyroxenes, Am. Mneral., 56, 72-89, 1971.

Wood, B. J., and S. Banno, Garnet-orthopyroxene and orthopyroxene-clinopyroxene relationships in simple and complex systems, Contrlb. Mineral. Petrol., 12, 109-142, 1973.

Wood, C. A., and L. D. Ashwal, SNC meteorites: Igneous rocks from Mars?, Proc. Lunar Planet. Scl. Conf., 12th, 1359-1375, 1981.

E. A. Cloutis, 4 Huntstrom Road NE, Calgary, Alberta Canada T2K 5W3.

M. J. Gaffey, Department of Geology, West Hall, Rensselaer Polytechnic Institute, Troy, NY 12181.

(Received November 15, 1990; revised September 16, 1991; accpted October 2, 1991.) 